\title{
TIx-1 and T/x-3 Homeobox Gene Expression in Cranial Sensory Ganglia and Hindbrain of the Chick Embryo: Markers of Patterned Connectivity
}

\author{
Cairine Logan, Richard J. T. Wingate, lan J. McKay, and Andrew Lumsden \\ Department of Developmental Neurobiology, United Medical and Dental Schools, Guy's Hospital, London SE1 9RT, \\ United Kingdom
}

Recent evidence suggests that in vertebrates the formation of distinct neuronal cell types is controlled by specific families of homeodomain transcription factors. Furthermore, the expression domains of a number of these genes correlates with functionally integrated neuronal populations. We have isolated two members of the divergent T-cell leukemia translocation (HOX11/TIX) homeobox gene family from chick, T/x-1 and T/x-3, and show that they are expressed in differentiating neurons of both the peripheral and central nervous systems. In the peripheral nervous system, $T / x-1$ and $T / x-3$ are expressed in overlapping domains within the placodally derived components of a number of cranial sensory ganglia. $T / x-3$, unlike $T / x-1$, is also expressed in neural crest-derived dorsal root and sympathetic ganglia. In the CNS, both genes are expressed in longitudinal

Subdivisions of a given neural system arise by diversification of its component cell types and pathways. During development, precursors must be differentially specified so that each functionally distinct population can form connections with its correct afferent and efferent targets. A major challenge in understanding the ontogeny of neural systems is determining how this correlated specification of neurons and their connections is achieved.

In the developing chick cranial sensory system, axons from the cranial ganglia enter the hindbrain and then turn sharply to form a series of ascending and descending tracts in the lateral portion of the pons and medulla (Kuhlenbeck 1973). These incoming afferents connect to different pools of second-order sensory neurons arranged in longitudinal columns. The emergent nuclear structures form longitudinal arrays that transect the early segmen-

\footnotetext{
Received Feb. 2, 1998; revised April 28, 1998; accepted May 6, 1998.

This work was supported by the Wellcome Trust, the United Kingdom Medical Research Council, and the Howard Hughes Medical Institute, of which A.L. is an International Research Scholar. C.L. was supported by the Medical Research Council of Canada and the International Human Frontier Science Program Organization. R.J.T.W. was a Medical Research Council of the United Kingdom Training Fellow. We thank Iano Campbell for excellent technical assistance, Anthony Graham and Gilles Fortin for helpful suggestions and discussions, Jon Gilthorpe for help with computing, and Nathalie Choussat for her help with preliminary analyses. The antibodies for $\mathrm{r} 5$-vimentin, Islet-1/2, and the probe for human Hox-11 were generous gifts from Ursula Dräger, Thomas Edlund, and Stanley Korsmeyer, respectively.

Correspondence should be addressed to Andrew Lumsden, Department of Developmental Neurobiology, United Medical and Dental Schools, Guy's Hospital, London SE1 9RT, UK.

Dr. Logan's present address: Department of Anatomy and Neuroscience Research Group, Faculty of Medicine, University of Calgary, 3330 Hospital Drive Northwest, Calgary, Alberta T2N 4N1, Canada.

Dr. McKay's present address: Department of Periodontology, St. Bartholomew's and the Royal London School of Medicine and Dentistry, Turner Street, London E1 2AD, UK.

Copyright $(\subset) 1998$ Society for Neuroscience $\quad 0270-6474 / 98 / 185389-14 \$ 05.00 / 0$
}

columns of neurons at specific dorsoventral levels of the hindbrain. Each column has distinct anterior and/or posterior limits that respect inter-rhombomeric boundaries. Tlx-3 is also expressed in D2 and D3 neurons of the spinal cord. T/x-1 and $T / x-3$ expression patterns within the peripheral and central nervous systems suggest that Tlx proteins may be involved not only in the differentiation and/or survival of specific neuronal populations but also in the establishment of neuronal circuitry. Furthermore, by analogy with the LIM genes, TIx family members potentially define sensory columns early within the developing hindbrain in a combinatorial manner.

Key words: chick; Hox11; TIx-1; TIx-3; homeodomain; neurogenesis; sensory nervous system tal organization of the hindbrain (Lumsden and Keynes, 1989; Marín and Puelles, 1995). What factors organize this transformation from a segmental arrangement and, in particular, how do populations of hindbrain sensory neurons become specified to receive inputs from specific cranial ganglia?

Recent interest has focused on the role of families of transcription factors in defining distinct subsets of neurons. Differential expression of closely related POU-domain transcription factors (Turner et al., 1994) define different classes of retinal ganglion cells and somatosensory neurons (Xiang et al., 1995; Erkman et al., 1996). In the spinal cord (Tsuchida et al., 1994) and hindbrain (Varela-Echavarría et al., 1996), the differential expression of LIM-domain genes confers a "code" for specific subsets of motor neurons (Tanabe and Jessell, 1996). Intriguingly, transcription factors such as DRG-11 (Saito et al., 1995) and Phox2 (Tiveron et al., 1996; Pattyn et al., 1997) may also define synaptic pathways within a functional neuronal circuit. This raises the possibility that these genes function upstream of cell surface molecules such as the cadherins (Suzuki et al., 1997), LAMP (Pimenta et al., 1995) and BEN (Chédotal et al., 1996), which potentially mediate neuronal recognition during the development of specific connections.

A candidate transcription factor family that may play a role in the development of cranial sensory pathways is the divergent homeobox-containing gene family Tlx (T-cell leukemia translocation, also known as Hox11). Tlx-1 was originally identified in humans because of a chromosomal translocation (Dube et al., 1991; Hatano et al., 1991; Kennedy et al., 1991; Lu et al., 1991). The corresponding mouse homolog has a very complex pattern of expression within the developing embryo (Raju et al., 1993; Dear et al., 1995; Roberts et al., 1995) and has been shown to play a 
critical role in the normal development of the spleen (Roberts et al., 1994; Dear et al., 1995). Two additional family members have been isolated, Hox11L1/Tlx-2 and Hox11L2/Tlx-3 (Cheng and Mak, 1993; Dear et al., 1993). All Tlx family members are expressed in the central and/or peripheral nervous system (Cheng and Mak, 1993; Dear et al., 1993, 1995; Raju et al., 1993; Roberts et al., 1995; Hatano et al., 1997).

In this study, we have isolated two members of the $T l x /$ Hox 11 gene family from chick, $T l x-1$ and $T l x-3$, and characterized their expression in neural tissue during early development. $T l x$ family members not only appear to identify synaptic pathways (analogous to DRG-11 and Phox-2) within the cranial sensory system but may also represent a code (as with LIM- and POU-domain factors) for the identity of specific subsets of sensory ganglion neurons and their associated central nuclei.

\section{MATERIALS AND METHODS}

Isolation and characterization of cDNA clones. A 630 bp HindII-Apa I human HOX11 cDNA fragment (Hatano et al., 1991) containing the homeobox was used to screen a chick stage 12-15 $\lambda$ ZAPII cDNA library (kindly provided by Dr. Angela Nieto and Dr. David Wilkinson, National Institute for Medical Research, Mill Hill, London, UK). Approximately $2 \times 10^{6}$ recombinant cDNA clones were plated, transferred to a Hybond-N nylon membrane (Amersham International, Buckinghamshire, UK), and hybridized for $16 \mathrm{hr}$ under high-stringency conditions [50\% formamide, $5 \times$ saline-sodium phosphate-EDTA (SSPE), $2 \times$ Denhardt's solution, $10 \%$ dextran sulfate, $150 \mu \mathrm{g} / \mathrm{ml}$ salmon sperm DNA, and $1 \%$ glycine]. Final washes were done using $0.5 \times$ SSPE and $0.1 \%$ SDS at $60^{\circ} \mathrm{C}$. Positive clones were plaque-purified, and pSK plasmids were excised using Exassist helper phage (Stratagene, La Jolla, CA) according to the manufacturer's instructions. Clones were restrictionmapped, and relevant fragments were subcloned into pBluescript SK (Stratagene) or M13 mp18/mp19 for sequencing. Single- and/or doublestranded DNA was sequenced by the dideoxy chain termination method using the Sequenase DNA sequencing kit (United States Biochemicals, Cleveland, $\mathrm{OH}$ ) or using the Thermo Sequenase Dye Terminator cycle sequencing premix kit (Amersham International) with either commercially available or appropriate synthetic oligonucleotide primers. Ambiguous sequences were analyzed using the guanidine analog ITP. Sequences were determined for both strands, and all sequences were analyzed using the Geneworks sequence analysis program package (IntelliGenetics, Mountain View, CA).

In situ hybridization, immunohistochemistry, and sectioning. Wholemount in situ hybridization of intact embryos, dissected hindbrains, or dissociated cells was performed using nonradioactive digoxygeninlabeled RNA probes essentially as described by Wilkinson (1992). Embryos were staged according to the method of Hamburger and Hamilton (1951).

For Tlx-1 (GenBank accession number AF071874), an $\sim 800$ bp probe entirely contained within the $3^{\prime}$ untranslated region was made by cutting the cDNA internally with PstI and transcribing with T7. For Tlx-3 (GenBank number AF071875), an $\sim 500$ bp SstII fragment containing the homeobox was subcloned into pBluescript SK, the resulting plasmid digested with $B g l \mathrm{II}$ and transcribed using T7. A second, more divergent $300 \mathrm{bp}$ SmaI fragment located 5' of the homeobox was used to confirm specificity of the $T l x-3$ probe. Specimens were refixed using $3.5 \%$ paraformaldehyde in PBS and/or in methanol/DMSO (4:1) before immunohistochemistry, sectioning, and/or storing. In addition, for BrdU labeling, dissected hindbrains were treated with $2 \mathrm{~N}$ hydrochloric acid for $1 \mathrm{hr}$ at $37^{\circ} \mathrm{C}$.

Isl-1/2 protein was detected by whole-mount immunohistochemistry using a 1:200 dilution of the rabbit polyclonal $\alpha$ Isl-1/2 antibody (kindly provided by Dr. T. Edlund, Department of Microbiology, University of Umea, Umea, Sweden) as per the method described by Davis et al. (1991). Disassociated cells and BrdU-labeled, dissected hindbrains were immunostained as described previously by Lumsden and Keynes (1989). BrdU incorporation was revealed using a specific monoclonal antibody (Bio-Science Products AG, Emmenbrücke, Switzerland) at a 1:10 dilution. The mouse monoclonal anti- $\beta$-tubulin antibody (Sigma, St. Louis, MO), the anti-160 kDa neurofilament antibody RMO-270 (Zymed, San Francisco, CA), and the anti r5-vimentin antibody (kindly provided by Dr. Ursula Dräger, E. K. Shriver Center, Waltham, MA) were used at
1:200, 1:2000, and 1:100 dilutions, respectively. HRP- or fluoresceinconjugated secondary antibodies to rat or mouse IgG and IgM (Jackson ImmunoResearch, West Grove, PA) were used where appropriate, at a 1:200 dilution.

After whole-mount in situ hybridization and/or immunohistochemistry, selected embryos were embedded in a mixture of gelatin and albumin, and $25-50 \mu \mathrm{m}$ transverse sections were cut using a vibratome. Sections were then cleared using $90 \%$ glycerol in PBS and mounted under coverslips for photography. BrdU-labeled hindbrains were similarly embedded and sectioned either coronally or parasagitally, and fluorescent cell nuclei were visualized by confocal microscopy (MRC 600; Bio-Rad, Welwyn Garden City, UK).

Labeling of S-phase nuclei with BrdU. Hens' eggs were incubated at $37^{\circ} \mathrm{C}$ in a humidified incubator. To prevent blood vessels forming over the roof of the shell, eggs were windowed at embryonic day 3 (E3) using a sharp pair of scissors and immediately resealed with heavy insulation tape ("tesa"; Beiersdorf AG, Hamburg, Germany). At E5, the window was opened again, and $6 \mu \mathrm{l}$ of bromodeoxyuridine (BrdU; $15 \mathrm{mg} / \mathrm{ml}$ in Howard's Ringer's solution) was injected via a glass micropipette into a blood vessel of the chorioallantoic membrane. Eggs were resealed and incubated at $37^{\circ} \mathrm{C}$ for either $30 \mathrm{~min}$ or $24 \mathrm{hr}$. After fixation in $3.5 \%$ paraformaldehyde in PBS, embryos were processed sequentially for in situ hybridization and immunohistochemistry.

Dissociated hindbrain cell cultures and intact hindbrain explants. Embryos were removed from the egg at 3-5 d of incubation, dissected free from surrounding membranes, and treated for 20-30 min with $1 \mathrm{mg} / \mathrm{ml}$ dispase in L-15 media. After rinsing several times with Howard's Ringer's solution, hindbrains [from rhombomeres 2 (r2) to r7 inclusive] were dissected free from surrounding tissue and washed two or three times with $\mathrm{Ca}^{2+}$ - and $\mathrm{Mg}^{2+}$-free HBSS containing $0.02 \%$ w/v EDTA (dissociation buffer). Dissected tissue was then incubated at $37^{\circ} \mathrm{C}$ for $15-20 \mathrm{~min}$ in fresh dissociation buffer containing between 5 and $50 \mu \mathrm{g} / \mathrm{ml}$ trypsin. After incubation, the tissue was mechanically disassociated using a firepolished Pasteur pipette coated with serum and pelleted for $5 \mathrm{~min}$ at low speed, and cells were resuspended in F-12 and SATO media (Bottenstein and Sato, 1979). Disassociated cells were rinsed twice with F-12 and SATO, plated onto poly-L-lysine- and laminin-coated plates, and placed in a $5 \% \mathrm{CO}_{2}$ incubator at $37^{\circ} \mathrm{C}$ in $\mathrm{F}-12$, SATO, and $10 \%$ heat-inactivated fetal calf serum for $20-24 \mathrm{hr}$. Cells were then fixed in $3.5 \%$ paraformaldehyde and processed sequentially for in situ hybridization and immunohistochemistry.

Hindbrains (from r1 to $\mathrm{r} 7$ inclusive) were similarly dissected from stage 16-17 (E3) chick embryos and embedded in collagen and DMEM. In some animals $(n=4)$, the fifth and seventh/eighth ganglia were removed. Hindbrain explants were bathed in modified F-12 and DMEM supplemented with chick embryo extract and antibiotics per the method of Book and Morest (1990) and incubated for $2 \mathrm{~d}$ in a $5 \% \mathrm{CO}_{2}$ incubator at $37^{\circ} \mathrm{C}$. Explants were then fixed in $3.5 \%$ paraformaldehyde and processed for in situ hybridization.

Axon tracing. The fifth and/or seventh/eighth cranial sensory nerves were anterogradely labeled in live embryos using lysinated rhodaminedextran (Molecular Probes, Eugene, OR). Briefly, hindbrains from stage 23 (E4) embryos were rapidly dissected in Howard's Ringer's solution, and the ganglion was cut at its root. Dextran (made up as a thick paste) was applied directly to the stump of the cranial nerve, and the isolated hindbrain $(n=7)$ was incubated at room temperature for $3 \mathrm{hr}$ in Howard's Ringer's solution before fixation in $3.5 \%$ paraformaldehyde and subsequent processing for in situ hybridization. Alternatively, DiI (Molecular Probes) dissolved in dimethylformamide $(6 \mathrm{mg} / \mathrm{ml})$ was used to similarly label sensory axons in paraformaldehyde (3.5\%)-fixed embryos. For labeling of the lateral longitudinal tract, DiI was injected into the roots of the fifth and/or seventh/eighth nerves of intact stage 29 (E6) embryos or into the caudal optic tectum of embryos at stage 19. Embryos were stored for up to $14 \mathrm{~d}$ at room temperature in $3.5 \%$ paraformaldehyde before dissection of the hindbrains for analysis. Dextran and DiI fluorescence was visualized by confocal microscopy (MRC 600; Bio-Rad).

\section{RESULTS}

\section{Isolation and characterization of chick Hox11/TIx homologs}

A total of five cDNA clones ranging in length from 1.7 to $2.2 \mathrm{~kb}$ were isolated by screening a chick stage 12-15 $\lambda$ ZAPII cDNA 


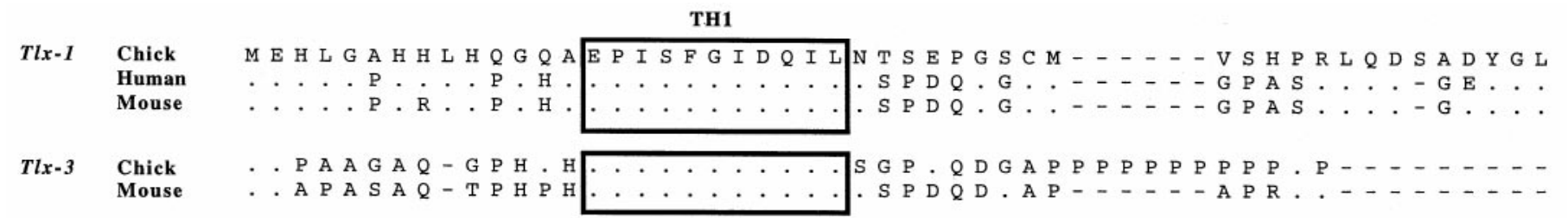

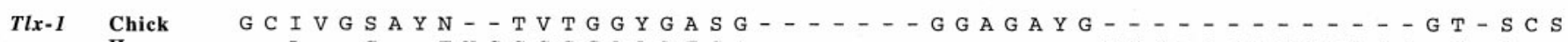
Human $\quad$. L . : G. T T G G G G S A A T G A - . . . . . . . . T G G P G P G G A G G G A . .

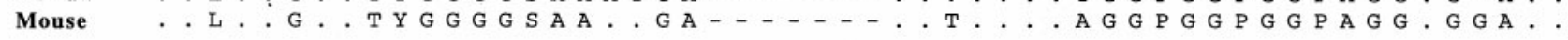

Tlx-3 Chick $\quad-\ldots-\cdots$ - P - P P P P R. P D. A A F G G P . G A P. P - - - - - - - A L P G P

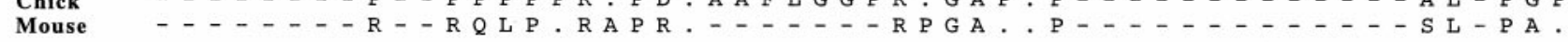

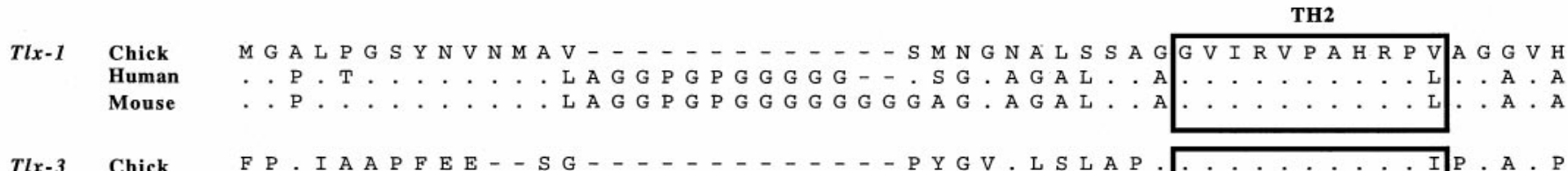

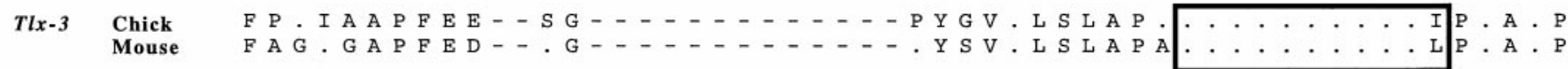

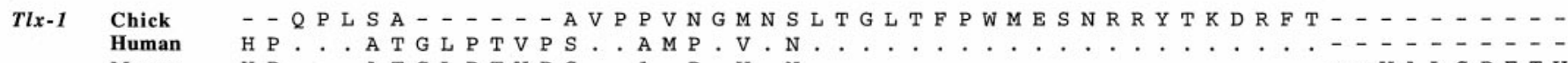

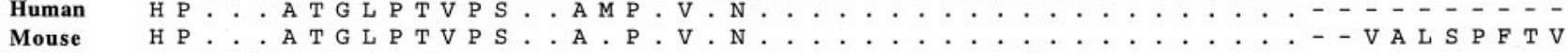

Tlx -3 Chick - - P. V P S A I P A V P - - - . - . . . . S....... S. . F V. E. . . A A A L T P F T V

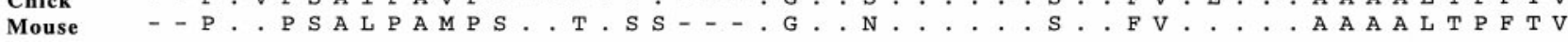

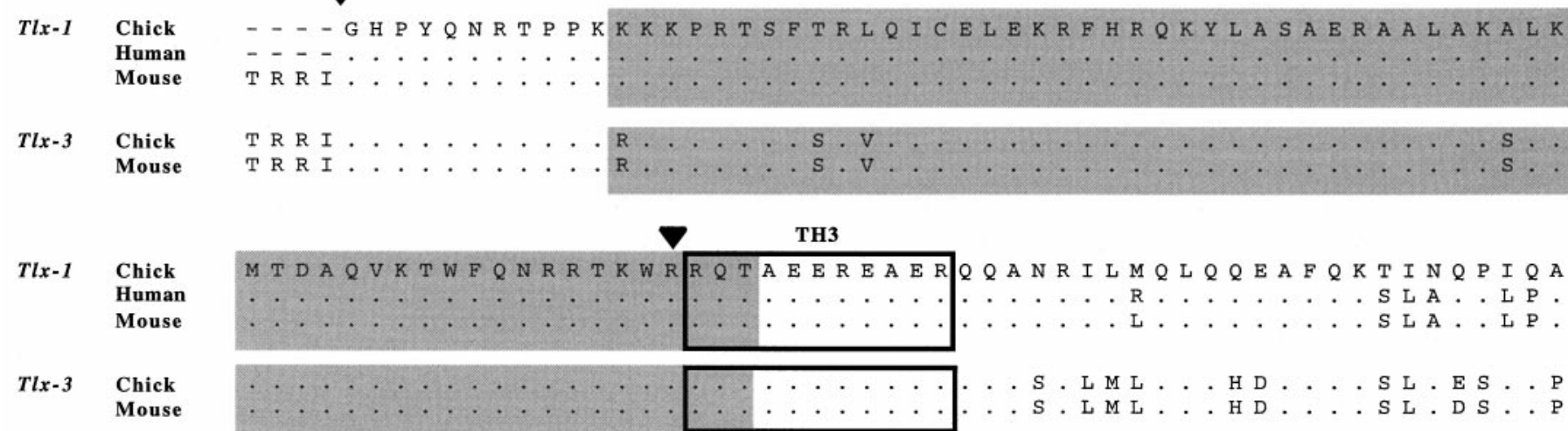

TH4

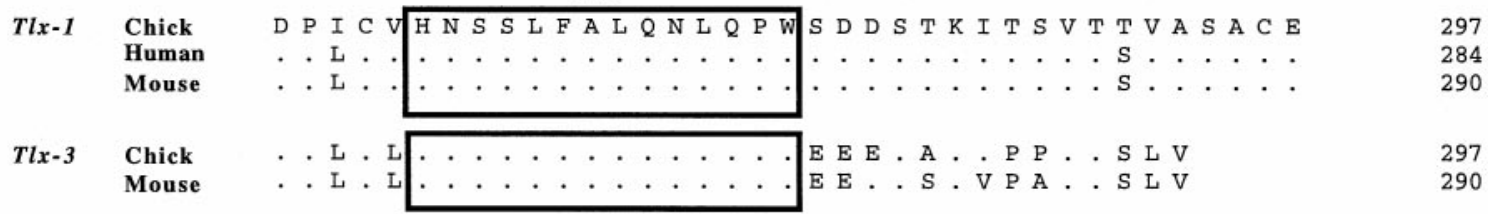

Figure 1. Comparison of Tlx-related proteins. The predicted protein sequences for the chicken $T l x-1$ and $T l x-3$ genes as well as their previously described human (Hatano et al., 1991) and/or mouse (Dear et al., 1993) homologs are aligned. The homeodomain is shaded. Four other highly conserved motifs, previously designated TH1-TH4 (Cheng and Mak, 1993), are enclosed in boxes. Amino acid identity is indicated by dots. Dashes correspond to gaps introduced to maximize alignment. The length of each protein is indicated numerically, and the position of the introns is indicated by a triangle.

library at high stringency using the human $H O X 11$ homeobox fragment (Hatano et al., 1991) as a probe. Restriction mapping and subsequent sequence analysis revealed that these clones, which we designate $T l x-1$ and $T l x-3$, corresponded to two different members of the previously identified Hox11/Tlx gene family (Cheng and Mak, 1993; Dear et al., 1993). Four of the five clones overlapped and were most closely related to Hox11 (also known as $T(x-1)$, whereas the fifth was most closely related to Hox11L2 (also known as $T l x-3$ ). A comparison of the predicted amino acid sequences for the two chick genes and their previously identified human (Hatano et al., 1991) and/or mouse (Dear et al., 1993) homologs is shown in Figure 1. Overall, the chick Tlx-1 homolog 

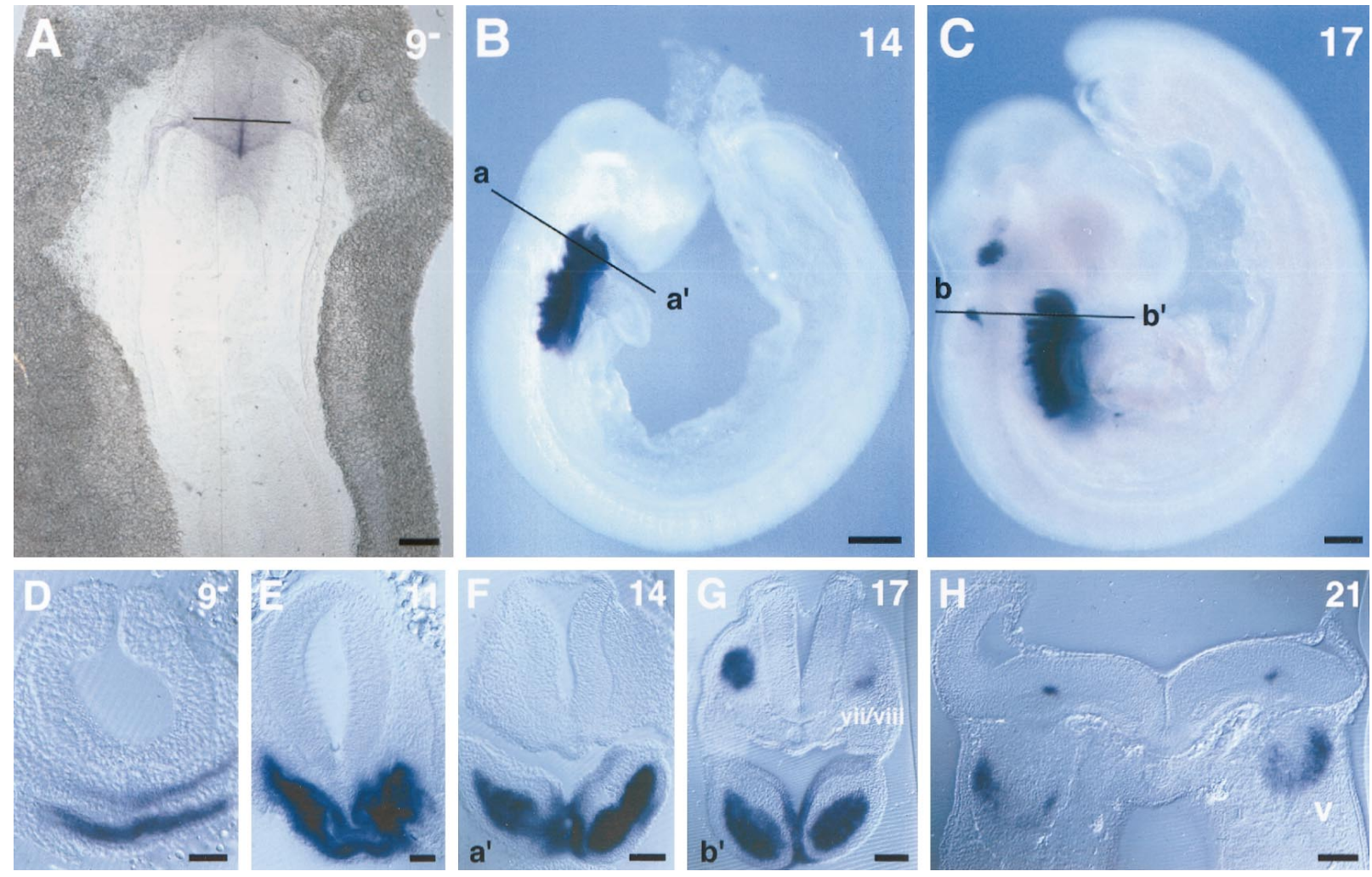

Figure 2. Early embryonic expression of Tlx-1. In situ hybridization analysis of Tlx-1 mRNA expression (blue) in intact embryos $(A-C)$ or transverse $50 \mu \mathrm{m}$ sections $(D-H)$. Embryonic stages are indicated numerically. The solid black lines in $A-C$ indicate the approximate level and orientation of the corresponding sections shown in $D, F$, and $G$ respectively. $A, D$, Ventral view $(A)$ and section $(D)$ through a stage $9^{-}$embryo. At this stage, $T l x-1$ transcripts are detected medially beneath the developing neural plate in definitive pharnygeal endoderm as well as in endoderm of the anterior intestinal portal. $E$, Similar transverse section of a stage 11 embryo showing that $T l x-1$ expression now extends into the mesenchyme. $B, F$, Lateral view $(B)$ and section $(F)$ through a stage 14 embryo (note that the rostral forebrain has been excised to prevent trapping of the in situ hybridization reaction product). Expression is concentrated within the developing branchial arches where it is restricted to the central mesenchyme and ventral medial endoderm and ectoderm. No expression is detected within the developing cranial ganglia. $C, G$, Lateral view $(C)$ and section $(G)$ through a stage 17 embryo. Expression persists within the developing branchial arches. At this stage, ganglia of the fifth and eighth (vii, viii) cranial nerves also express $T l x-1$. $H$, Transverse section through a stage 21 embryo. Expression in the trigeminal ganglia $(V)$ is restricted to cells that are distal from the nerve root. Within the hindbrain, Tlx-1 expression is confined to a bilaterally symmetrical population of cells located at the interface between the ventricular layer and the mantle. Scale bars: $D, E, 100 \mu \mathrm{m}$; all other panels, $200 \mu \mathrm{m}$.

was found to share greater amino acid sequence identity with the human and mouse Hox11/Tlx-1 proteins (81\% for each, respectively) than it does with the mouse Hox11L1 (63\%) or Hox11L2 $(64 \%)$ proteins, not including deletions and insertions. Similarly, the chick Tlx-3 homolog was $85 \%$ identical to Hox11L2 overall, although it shares only $64-70 \%$ identity with the human and/or mouse Hox11/Tlx-1 and Hox11L1/Tlx-2 proteins, respectively. Furthermore, the 60 amino acid homeodomain of chick Tlx-1 and Tlx-3 are $100 \%$ identical to that found in their respective mouse and/or human homologs. Notably, the two chick homeodomains, like other members of this gene family, both contain a threonine at position 47 . In both Tlx-1 and Tlx-3 proteins, there also exists considerable sequence similarity across species in the regions immediately surrounding the homeodomain.

Previous studies have shown that members of the Hox11/Tlx gene family share four other highly conserved motifs designated TH1-TH4 (Cheng and Mak, 1993) in addition to the highly conserved homeodomain. Two of the four motifs, TH1 and TH2, lie N-terminal of the homeodomain and are $100 \%$ identical or have a single conservative amino acid substitution, respectively, in the chick Tlx proteins. Similarly, the TH3 and TH4 motifs, which lie C-terminal of the homeodomain, are $100 \%$ identical.

\section{Embryonic expression of $T / x-1$ and $T / x-3$}

We have examined the spatial and temporal pattern of $T l x-1$ and Tlx-3 mRNA expression during early chick embryogenesis by in situ hybridization. With some notable exceptions, especially involving the nervous system, the $T l x$ expression data presented here are in agreement with those described previously in mouse (Cheng and Mak, 1993; Raju et al., 1993; Roberts et al., 1994, 1995; Dear et al., 1995). In particular, Tlx-1 is expressed early in the developing branchial arches, subsequently in the sensory components of the fifth and eighth cranial nerves and later in longitudinal stripes in the hindbrain. In addition, expression is observed in the thoracic region, in the presumptive pharynx, and in a portion of the heart (data not shown). In the gut region, there is prominent expression from stage 20 onward in mesenchymal cells of the dorsal mesentery that corresponds to the splenic primordium (data not shown).

In contrast, $T l x-3$ expression is restricted to neuronal populations within the peripheral and central nervous systems. In the peripheral nervous system, $T l x-3$ is expressed in the placodederived components of several cranial sensory ganglia and in the neural crest-derived dorsal root and symphathetic ganglia. In the CNS, $T l x-3$ is expressed in two longitudinal columns of neurons 

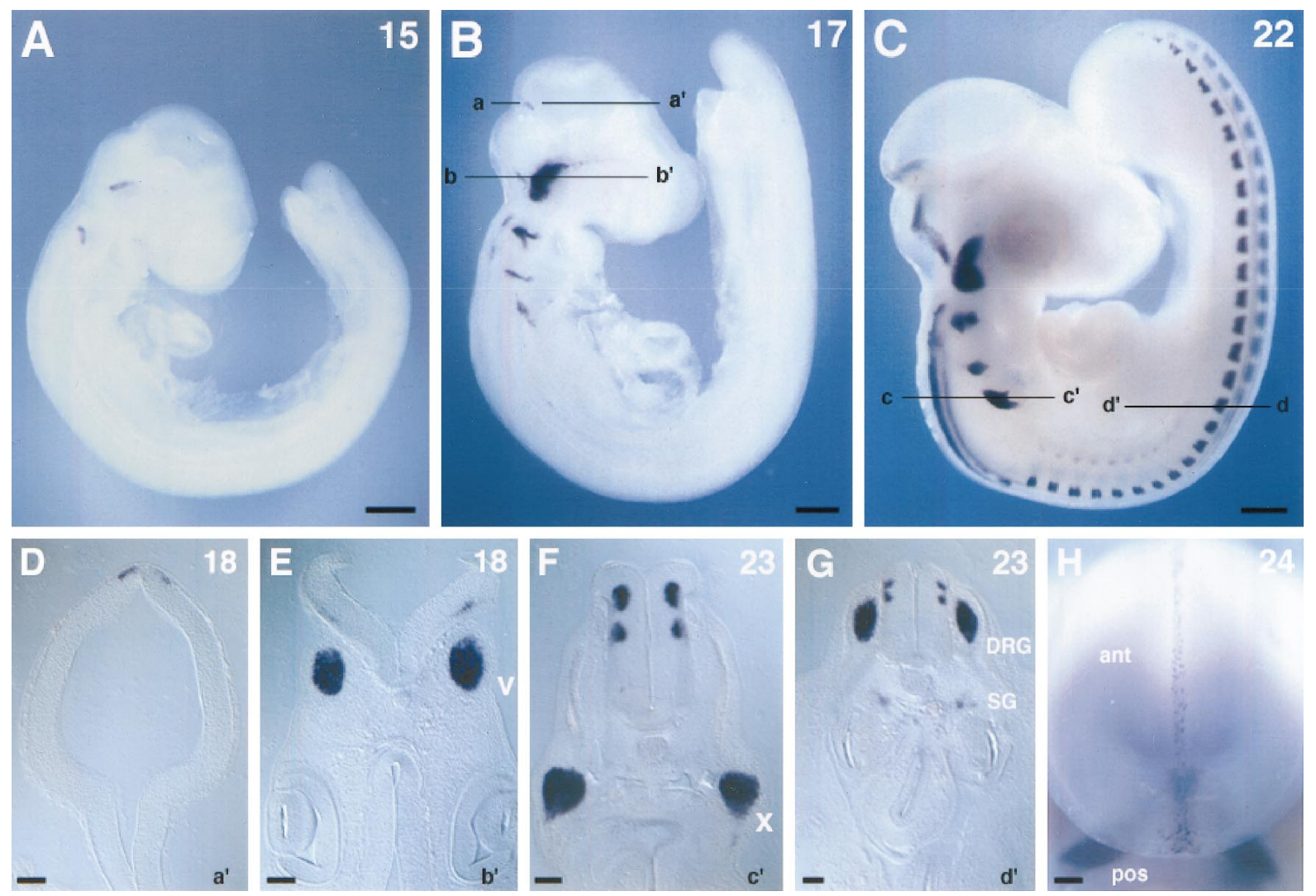

Figure 3. Early embryonic expression of $T l x$-3. In situ hybridization analysis of $T l x-3$ mRNA expression (blue) in intact embryos $(A-C, H)$ or transverse $50 \mu \mathrm{m}$ sections $(D-G)$. Embryonic stages are indicated numerically. The solid and/or broken black lines in $B$ and $C$ indicate the approximate level and orientation of the transverse sections of the similarly staged embryos shown in $D-G$. $A$, Lateral view of a stage 15 embryo. Tlx-3 transcripts are first detected within the ophthalmic lobe of the trigeminal and throughout the vestibuloacoustic ganglion. $B$, Lateral view of a stage 17 embryo showing expression in the developing 5th-10th cranial ganglia. By this stage, $T l x-3$ expression extends into the maxillomandibular lobe of the trigeminal (5th) ganglion. It is clear that, in contrast to $T l x-1$ (Fig. 2C), $T l x-3$ labels both the seventh and eighth ganglia. Expression can also be seen along the dorsal midline in the developing mesencephalon and in even numbered rhombomeres in the hindbrain. $C$, Lateral view of a stage 22 embryo. By this stage, the cranial, dorsal root and symphathetic ganglia all express $T l x-3$. Two bilateral columns of $T l x$-3-expressing cells can also be seen caudally in the developing hindbrain and throughout the spinal cord. $T l x-3$, unlike $T l x-1$, is also expressed laterally in a bilaterally symmetrical broad domain within r1. Expression also persists in scattered cells on either side of the dorsal midline in the developing mesencephalon and posterior diencephalon. $D$, Horizontal section (at approximately $a-a^{\prime}$ ) of a stage 18 embryo showing expression at the dorsal midline of the caudal mesencephalon. $E$, A more caudal section (at approximately $b-b^{\prime}$ ) through the same embryo showing that $T l x-3$ is expressed in the hindbrain in a bilaterally symmetrical broad domain located at the interface between the ventricular layer and the mantle. Peripherally, expression can be seen within the trigeminal ganglion (V). $F$, Transverse section (at approximately $c-c^{\prime}$ ) of an older (stage 23) embryo showing that $T l x-3$ is now expressed in two bilateral domains within the caudal hindbrain and in the more distal (nodose) ganglion of the 10th cranial nerve $(X)$. $G$, A more caudal section (at approximately $\left.d-d^{\prime}\right)$ through the same embryo showing that the two bilateral columns of $T l x$-3-positive central neurons continue into the spinal cord. Expression is also seen in the dorsal root ganglion $(D R G)$ and sympathetic ganglion $(S G) . H$, Dorsal view of the mesencephalon of a stage 24 embryo showing $T l x-3$ expression in scattered cells on either side of the dorsal midline; ant, anterior; pos, posterior. Scale bars: $A, B, H, 200 \mu \mathrm{m} ; C, 400 \mu \mathrm{m} ; D-G, 100 \mu \mathrm{m}$.

at distinct dorsoventral levels of the hindbrain, as well as in D2 and D3 neurons within the spinal cord.

\section{TIX-1 is expressed early in the developing branchial arches}

Tlx-1 transcripts are first detected at the three-somite stage (stage $8^{-}$) in the definitive pharnygeal endoderm. Slightly later, beginning at 5 somites (stage $8^{+}$), endoderm of the anterior intestinal portal also begins to express $T l x-1$ (Fig. $2 A, D)$. At stage 11 (13 somites), both the endoderm as well as mesenchyme express $T l x-1$ (Fig. 2E). As the branchial arches develop, Tlx-1 expression becomes restricted primarily to the central mesenchyme and ventral medial endoderm and ectoderm (Fig. 2F,G). Expression persists within the developing branchial arches until at least stage 25 , the latest stage examined. However, by this stage expression is barely detectable within the mandibular component of the first branchial arch. Expression was not detected at any stage in the maxillary component of the first branchial arch.

\section{TIx-1 and T/x-3 are expressed in overlapping domains within the sensory components of the fifth and eighth cranial nerves}

At stage 15, the ganglia of the fifth (trigeminal) and eighth (vestibuloacoustic) cranial nerves begin to express both $T l x-1$ and $T l x-3$ (Fig. $3 A$; data not shown). Although $T l x-3$ expression is initially restricted to the ophthalmic lobe of the trigeminal ganglion (Fig. $3 A$ ), it soon extends into the maxillomandibular lobe where it overlaps with that of $T l x-1$. By stage 17 (Figs. 2C, 3B), both genes are strongly expressed in overlapping domains within the ganglia of the vestibuloacoustic nerve (eighth). Overlapping expression of $T l x-1$ and $T l x-3$ is also seen within the ventrolateral portion of the maxillomandibular lobe of the trigeminal ganglion. At this stage, weak $T l x-1$ expression also becomes apparent and overlaps with that of $T l x-3$ within the ophthalmic lobe. $T l x-3$, unlike $T l x-1$ is also expressed in the distal, placode-derived geniculate, petrosal, and nodose ganglia of the 7th, 9th, and 10th 


\section{TIX-1}
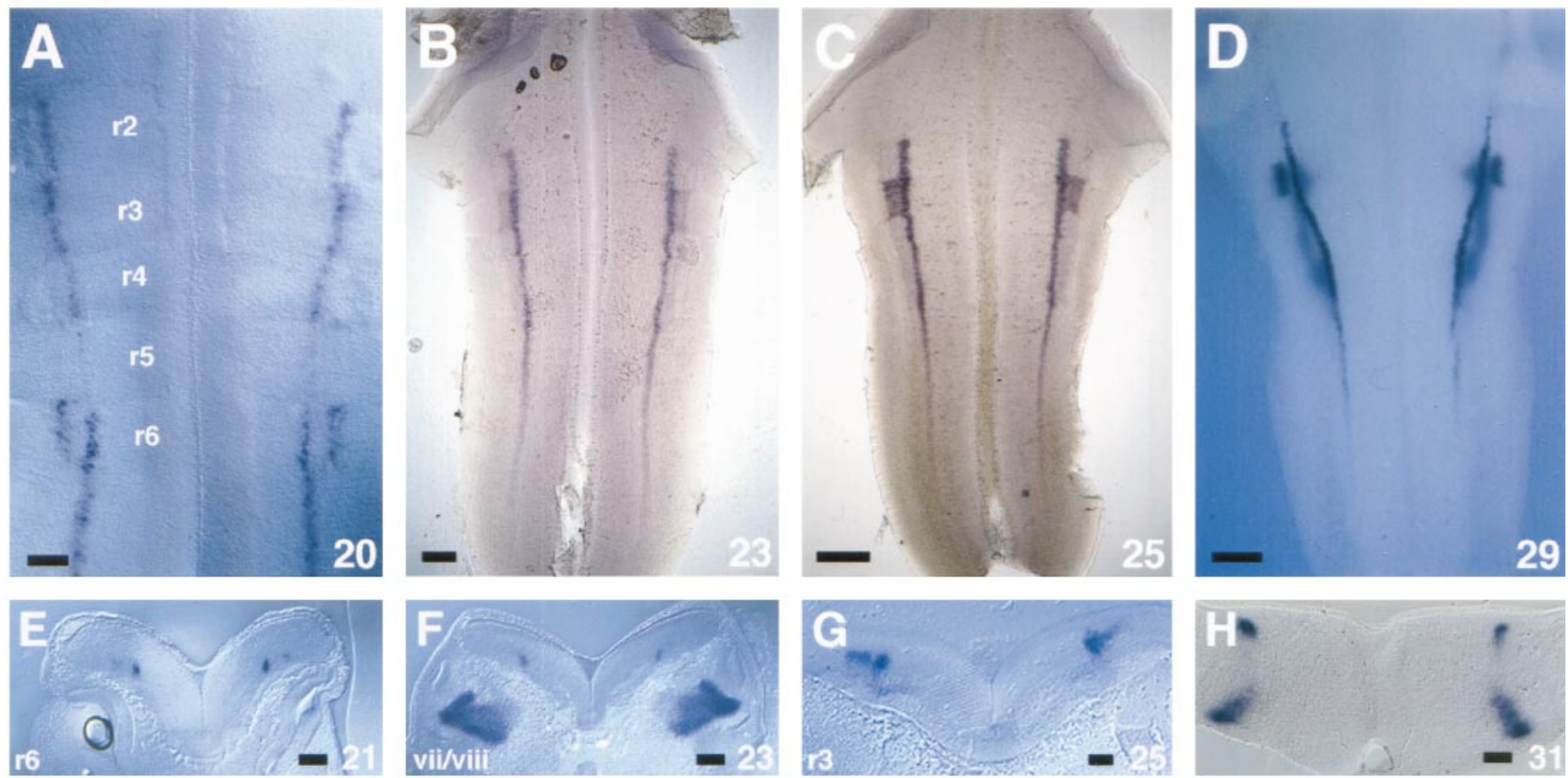

\section{TIX-3}
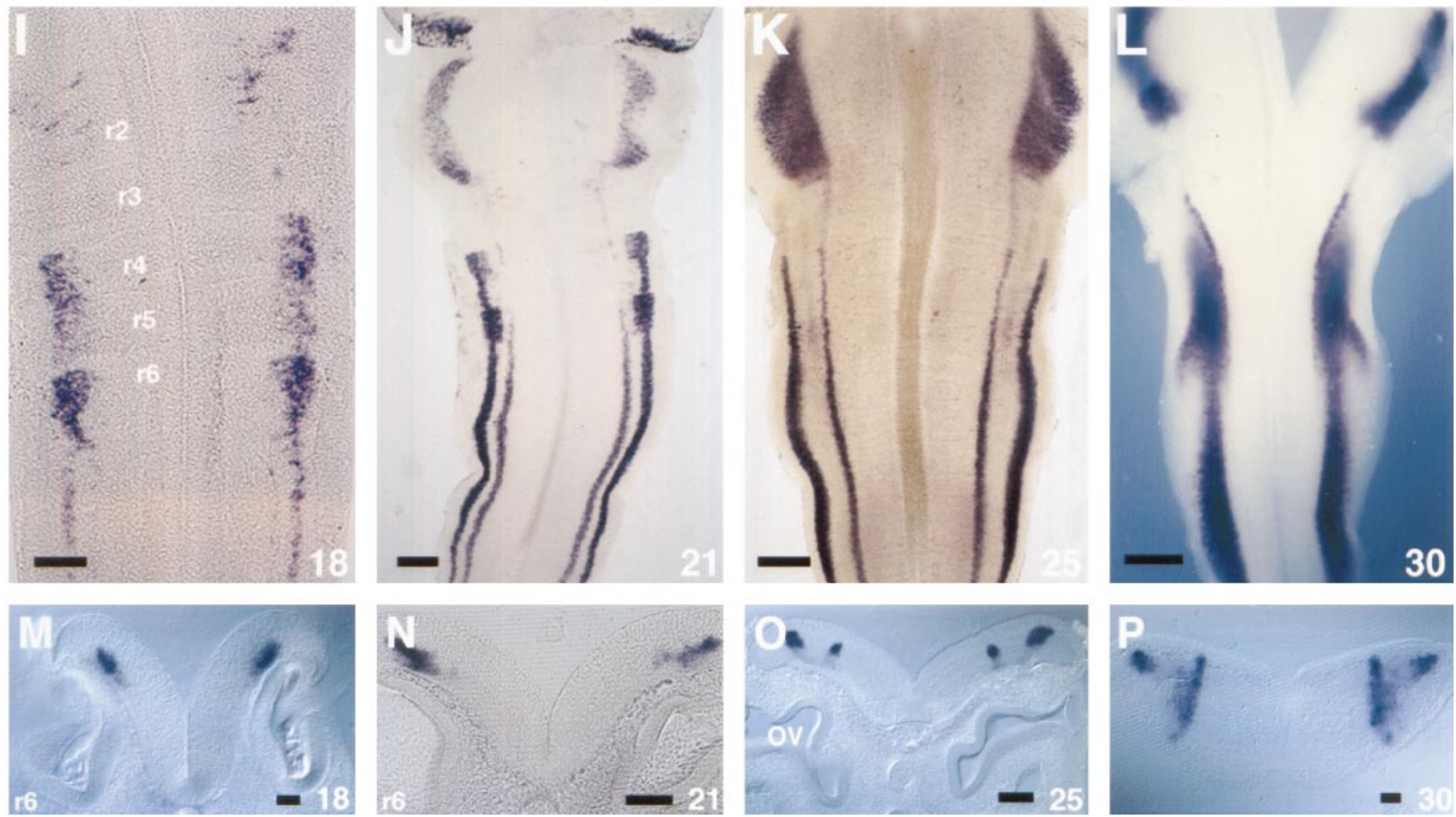

Figure 4. Tlx-1 and Tlx-3 expression in the developing hindbrain. In situ hybridization analysis of $T l x-1$ ( $A-H$, top panels) and Tlx-3 (I-P, bottom panels) mRNA expression (blue) in E4-E7 hindbrains. Within each set of panels, the top rows $(A-D, I-L)$ show dissected and flat-mounted hindbrains viewed from the ventricular surface. The bottom rows $(E-H, M-P)$ show $50 \mu \mathrm{m}$ transverse vibratome sections of similarly staged embryos. Numbering in the bottom right corner of each panel refers to embryonic stages. Where appropriate, the rhombomeric location of transverse sections is also given. $A$, $T l x-1$ expression at stage 20 is limited to a single stripe running caudally from the $\mathrm{r} 1-\mathrm{r} 2$ boundary. The onset of expression is delayed in $\mathrm{r} 5$, and a more lateral, parallel band of expression is transiently present in r6. Discontinuities in label at rhombomere boundaries are caused by blood vessels forming preferentially at segment interfaces (Noden, 1992). At these points, the expression of Tlx-1 is not interrupted but is located deeper into the mantle and hence outside the plane of focus. $B$, At stage 23 , the domain of expression has resolved to a single continuous bilaterally symmetrical column of cells. (Figure legend continues) 
cranial nerves, respectively (Fig. 3B, $C$; see Fig. 7). The rostrocaudal order of onset of $T l x-3$ expression within these ganglia is slightly delayed with respect to the fifth and eighth ganglia.

To assess the neuronal phenotype of Tlx-1- and Tlx-3expressing cells within cranial sensory ganglia, stage 21-25 embryos were processed sequentially via in situ hybridization using Tlx-1- or Tlx-3-specific mRNA probes and immunohistochemically using the $\alpha$ Isl-1/2 antibody; a marker that labels neurons within cranial sensory ganglia. $T l x-1$ and $T l x-3$ transcripts were found to colocalize with Isl-1/2 protein (see Fig. $6 F$ and data not shown). Furthermore, at later developmental stages (Fig. $2 H$; see Fig. $6 F$ ), their expression within the maxillomandibular lobe of the trigeminal ganglia is clearly restricted to the larger, more distally located, placodally derived neurons.

By stage 25, Tlx -1 expression within the trigeminal ganglion is greatly reduced. However, expression within the vestibuloacoustic ganglia remains strong until at least stage 28 (data not shown). $T l x-3$ expression is significantly reduced in the seventh, eighth, and ninth ganglia by stage 25 .

\section{TIX-1 is expressed in parallel, bilateral stripes running rostrocaudally at distinct dorsoventral levels within the developing hindbrain}

Tlx -1 is expressed in the hindbrain from stage 20 (E3.5) until at least stage 35 (E9), the latest stage examined. Figure $4 A-D$ shows the dorsal view of dissected and flat-mounted stage 20-29 hindbrains in which the roof plate of the fourth ventricle has been removed. Initially, $T l x-1$ expression is for the most part restricted dorsoventrally and anteroposteriorly to a single, bilateral stripe that runs caudally from the boundary between $\mathrm{r} 1$ and $\mathrm{r} 2$ into the cervical spinal cord. The stripe itself reflects the underlying segmental organization of the hindbrain (for review, see Lumsden, 1990). It is staggered at each successive rhombomere boundary, and there are transient rhombomere-specific elaborations of the $T l x-1$ expression pattern. For example, in Figure 4, a comparison between $A$ (stage 20) and $B$ (stage 23) reveals that the onset of $T l x-1$ is delayed in $\mathrm{r} 5$, whereas in $\mathrm{r} 6$ there is initially a second parallel and more dorsal stripe of $T l x-1$ expression. Similarly, the stripe of expression within $\mathrm{r} 3$ begins to widen dorsally at stage 23 (Fig. 4B), becomes more pronounced by stage 25 (Fig.
$4 C$ ), and by stage 29 (Fig. 4D, see Fig. 7) has resolved into a second stripe - a pattern evocative of medial to lateral cell migration. Diff use Tlx-1 staining extending from the caudal end of the hindbrain through the tail region is also seen in the developing spinal cord (data not shown).

Coronal sections at stages 21, 23, and 25 (Figs. 4E-G) show that Tlx-1-positive cells are located at the distal (pial) edge of the ventricular zone at the interface between nuclei of dividing cells and the postmitotic cells of the mantle. At these stages, however, the mantle is relatively thin. As an increasing number of cell bodies are deposited, the stripe of $T l x-1$ expression segregates into parallel pial and ventricular components. By stage 29-31, $T l x-1$ expression is clearly organized into complementary stripes at different depths within the hindbrain (Fig. 4D, $H$ ). The more discrete ventricular stripe retains a segmental organization, despite the fact that the overtly segmented structure of the hindbrain disappears after stage 24-25. The pial stripe of expression extends anteroposteriorly from approximately the r2-r3 boundary to the r6-r7 boundary (see Fig. 7). Interestingly, from stages 25 to 28 , a curtain of label stretches between the ventricular and pial stripes, again highly evocative of cell migration. Within the pial stripe of expression, two foci of concentrated label are apparent at the level of r3 and r6.

By stage 34, both the ventricular and pial stripes of Tlx-1 expression are significantly decreased. However, the two foci of label within the pial stripe remain distinct, and by stage 35 , faint $T l x-1$ expression can be found only in these more pial foci (data not shown).

\section{TIx-1-expressing cells within the hindbrain are postmitotic neurons}

To assess the phenotype of $T l x$-1-positive cells within the hindbrain, short-term cultures of dissociated hindbrain cells from stage 21-25 embryos were processed sequentially via in situ hybridization using a $T l x-1$-specific mRNA probe and immunohistochemically using specific neuronal or glial markers. As shown in Figure $5 A$, all $T l x$-1-positive cells coexpressed $\beta$-tubulin protein, an early neuronal marker. Similarly, most $T l x-1$-expressing cells were positive for a second neuronal-specific antigen, RMO-270 (Fig. $5 B$ ), which identifies the $160 \mathrm{kDa}$ neurofilament subunit of

\section{$\leftarrow$}

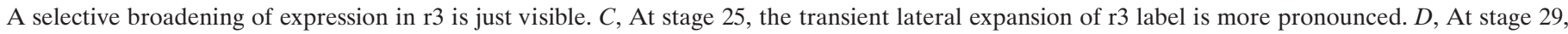

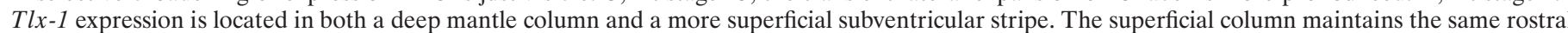

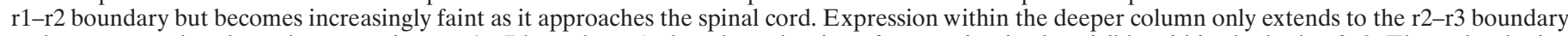

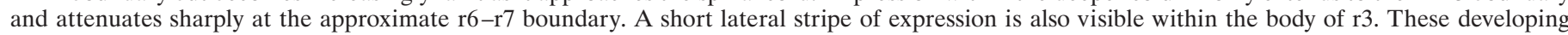

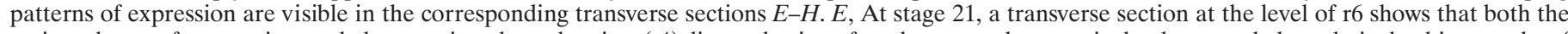

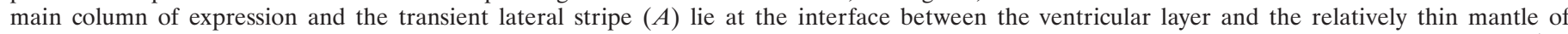

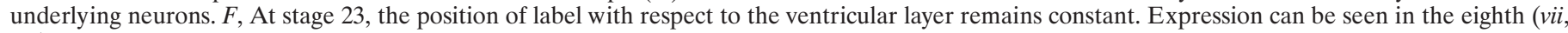

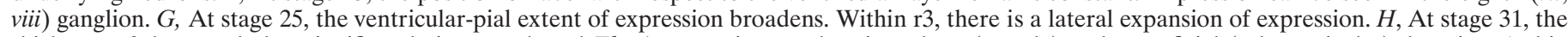

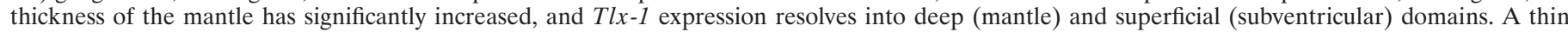

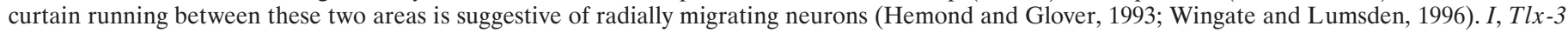

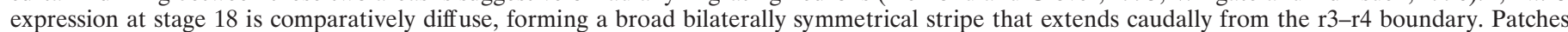

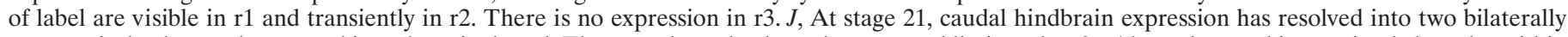

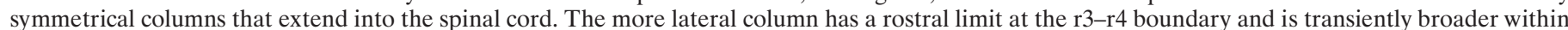

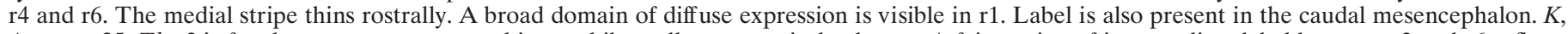

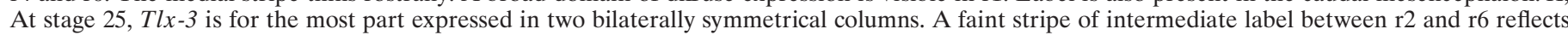

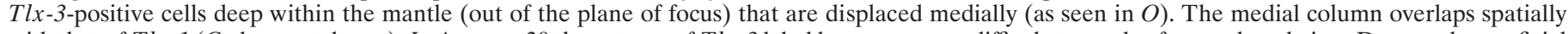

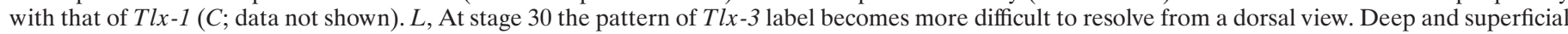

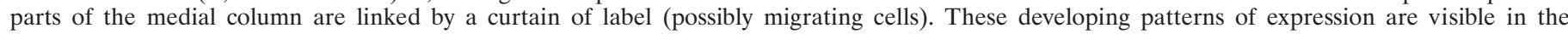

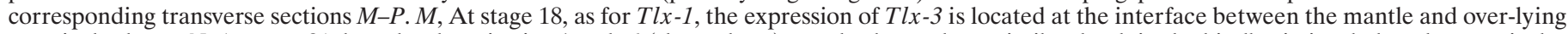

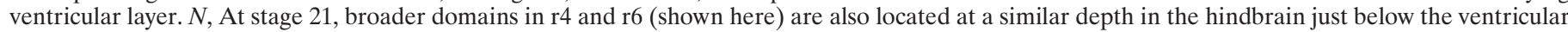

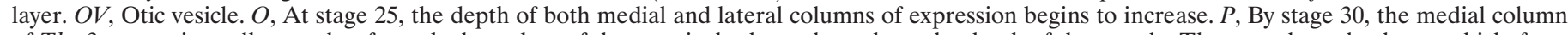

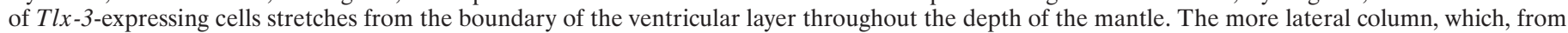

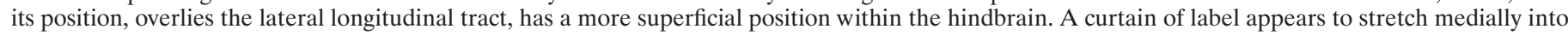
the expanding mantle layer. Scale bars: $C, D, L, 200 \mu \mathrm{m}$; all other panels, $100 \mu \mathrm{m}$. 

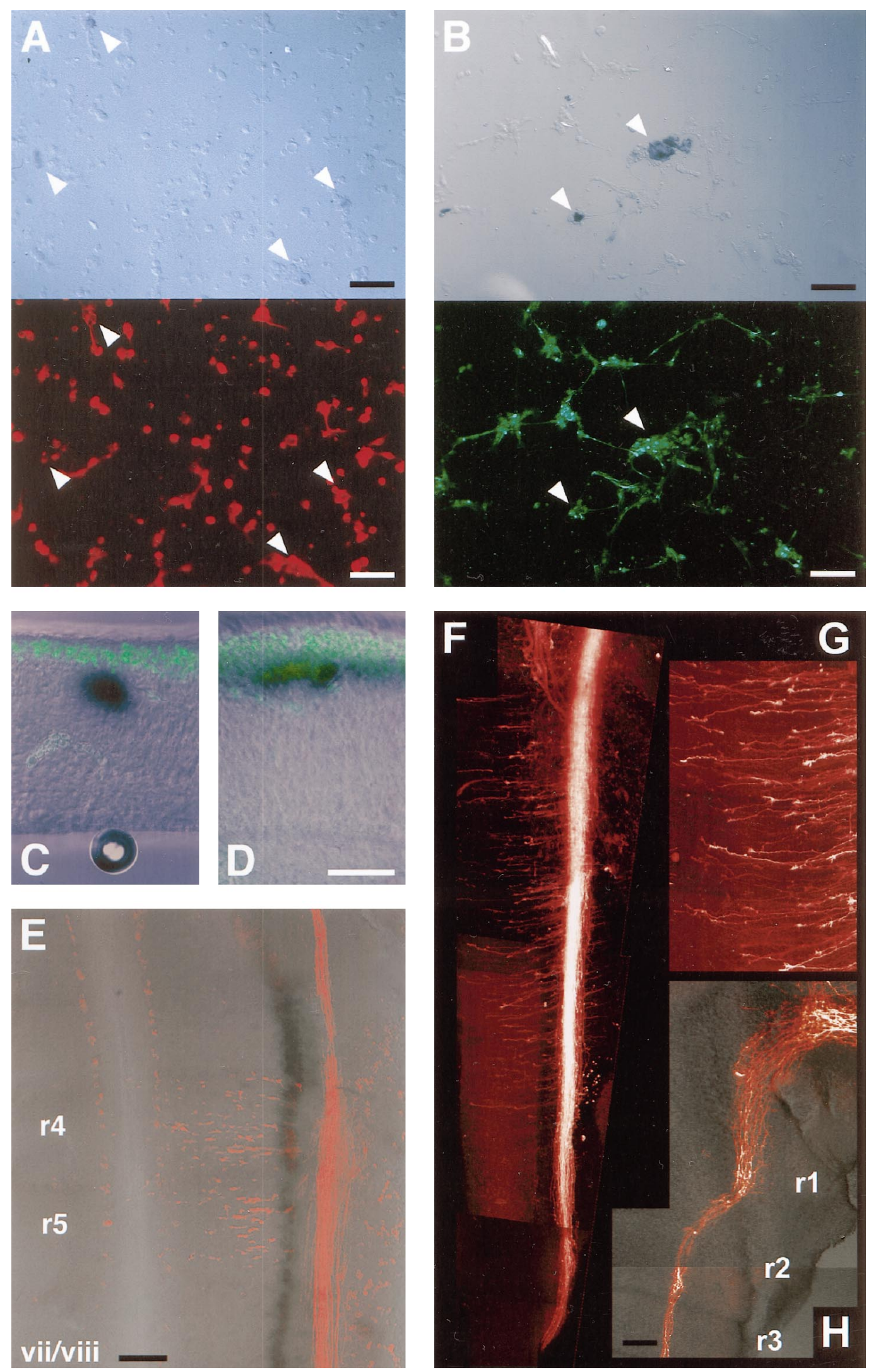

Figure 5. Characterization of the identity and position of $T l x-1$ expressing cells within the developing hindbrain. $A, B$, Colocalization of $T l x-1$ mRNA and $\beta$-tubulin $(A)$ or the $160 \mathrm{kDa}(\mathrm{NF}-\mathrm{M})$ neurofilament protein $(B)$ in dissociated hindbrain cell cultures from stage $21-25$ embryos. The top panels in $A$ and $B$ show phase-contrast photomicrographs of the bright-field images. Tlx-1-positive cell bodies are stained blue. The same view under fluorescent illumination is shown in the bottom panels. Cells that express $\beta$-tubulin, an early neuronal marker, or the $160 \mathrm{kDa}(\mathrm{NF}-\mathrm{M})$ neurofilament protein, a marker of differentiated neurons, are stained red or green, respectively. Arrowheads mark examples of double-labeled cells. $C$, Confocal photomicrograph (Figure legend continues) 
differentiated neurons. In contrast, no cells were double-labeled in cultures similarly processed using the anti-vimentin antibody R5 (data not shown), a marker of radial glial cells (Dräger et al., 1984; Heyman et al., 1995).

Although the later pial stripe of $T l x-1$ expression at stage 29 undoubtedly consists of postmitotic cells, it was unclear whether the ventricular stripe of $T l x-1$ expression is located within the germinal zone or whether it lies just outside the layer of mitotic cells. To assess whether $T l x$-1-expressing cells within the hindbrain are mitotically active, we used BrdU to label cells in S-phase. Thirty minutes after BrdU treatment, it is clear that Tlx-1-positive cells do not incorporate BrdU but lie just outside the proliferative, ventricular zone (Fig. $5 C$ ). By comparison, Figure $5 D$ shows the pattern of double labeling in a parasagittal section of a $T l x$-1-expressing ventricular stripe in a stage 29 embryo $24 \mathrm{hr}$ after a similar injection of BrdU. During this period some BrdU-labeled cells will have become postmitotic and migrated out of the ventricular zone. A number of postmitotic Tlx-1-positive cells have incorporated BrdU, indicating that they have divided within the last $24 \mathrm{hr}$. This suggests that Tlx-1 expression within the hindbrain can be initiated in postmitotic neurons soon after they have undergone their final division.

\section{TIx-1-positive neurons are closely associated with the lateral longitudinal axonal tract and do not colocalize with Isl-1/2 protein}

Primary afferent axons derived from progressively more caudal cranial sensory ganglia course in successively more lateral positions within the lateral longitudinal tract of the hindbrain (Clarke and Lumsden, 1993). To examine the spatial relationship between the $T l x$-1-positive stripe of expression within the hindbrain and that of incoming axons, fluorescent rhodamine-dextran was used to label cranial nerve roots before in situ hybridization using a $T l x-1$-specific probe. Figure $5 E$ shows a flat-mounted stage 24 hindbrain revealing the close spatial relationship between $T l x-1$ positive cells (blue) and sensory axons of the seventh/eighth cranial nerve (red). Incoming sensory axons from the fifth cranial nerve would fill the gap between the seventh/eighth axon tract and the stripe of $T l x-1$ expression. Hence, the column of Tlx-1positive neurons lies just medial to the lateral longitudinal tract (Fig. $5 F$ ). Interestingly, DiI labeling from the fifth cranial nerve also reveals that the incoming afferents project numerous collaterals medially toward the position of the $T l x-1$ positive stripe (Fig. $5 G$ ).

Previous expression studies in mouse have suggested that $T l x-1$ marks branchial motor nuclei within the developing hindbrain (Roberts et al., 1994, 1995). To directly determine whether chick Tlx -1 is expressed in motor nuclei, hindbrains from stage 29-31 embryos were processed sequentially via in situ hybridization using a $T l x$ - 1 -specific probe and immunohistochemically using an $\alpha$ Isl-1/2 antigen that specifically labels all cranial motor nuclei within the developing hindbrain (Varela-Echavarría et al., 1996).
As shown in Figure $6 A-D$, Isl-1/2 protein does not colocalize with Tlx-1 mRNA transcripts.

\section{TIX-1 expression within the hindbrain is cell-autonomous}

Studies in both invertebrates (Macagno, 1979; Baptista et al., 1990; Selleck and Steller, 1991) and, more recently, vertebrates (Gong and Shipley, 1995) have shown that peripheral axons may be involved in the specification of neurons within the developing CNS. Both the onset of $T l x-1$ expression (initially peripheral and then progressively more central) and the position of $T l x-1$ positive hindbrain neurons just medial to the lateral longitudinal axonal tract suggest a correlation with the timing and trajectory of sensory axon innervation (Moody et al., 1989; Chédotal et al., 1995). Axons invade the hindbrain before the onset of Tlx-1 expression, and we sought to investigate whether fibers from the cranial ganglia might induce or potentiate expression of $T l x-1$ within the hindbrain. We tried a variety of surgical ablation and barrier approaches in ovo before deciding that the regenerative capacity and multiple origins of axons in the tract (from both cranial ganglia and midbrain) preclude a conclusive exclusion of axon ingrowth by these means. We therefore tested the ability of both cultured hindbrains deprived of their cranial ganglia and dissociated hindbrain cells to autonomously express $T l x-1$. Hindbrains explanted before the onset of $T l x-1$ expression with their cranial ganglia excised as well as dissociated hindbrain cells from similarly staged embryos; cultured for $1-2 \mathrm{~d}$, both expressed $T l x-1$ mRNA (data not shown). These findings suggest that the onset of Tlx-1 expression in the hindbrain is independent of afferent innervation and is cell-autonomous. Furthermore, dissociated cell cultures from stage 21-25 hindbrains (after the onset of $T l x-1$ expression) also expressed $T l x-1$ (Fig. $5 A, B$ ), suggesting that peripheral nerve innervation is not required for the maintenance of $T l x-1$ expression in central neurons.

\section{TIx-3 is also expressed in parallel, bilateral stripes running rostrocaudally at distinct dorsoventral levels within the developing hindbrain}

Tlx -3 transcripts are first detected in the hindbrain at stage 15. As shown in Figure $4 I-L$, expression for the most part is contained within two longitudinal columns of cells at specific dorsoventral levels. The more dorsally located column appears first and has a distinct rostral limit at the r3-r4 boundary (Figs. 4I, 7). The second, more medial column overlaps both spatially and temporally with that of $T l x-1$ (Fig. $4 J, K$; data not shown). However, rostrally it is much narrower and unlike $T l x-1$ continues into r1 where it expands dorsally. This expanded rostral expression of $T l x-3$ correlates precisely with a pronounced dorsal shift in the trajectory of axons and broadening of the lateral longitudinal tract within r1 (Fig. $5 H$ ). Caudally, both columns appear to

\section{$\leftarrow$}

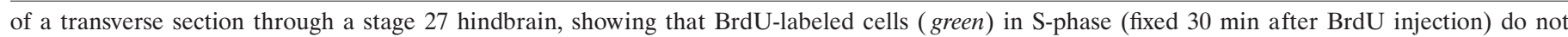

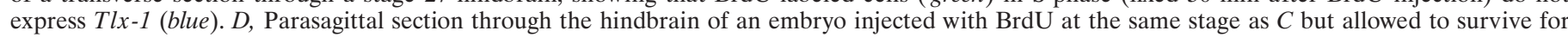

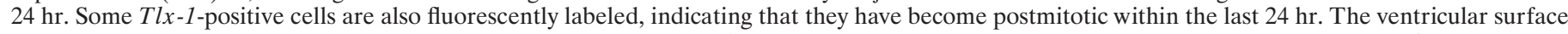

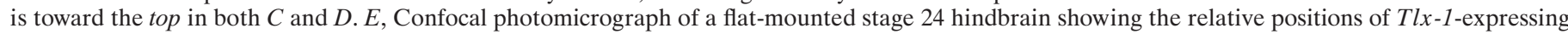

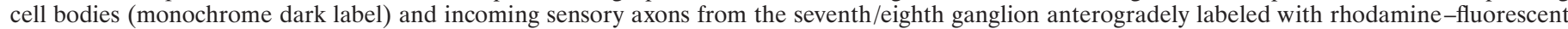

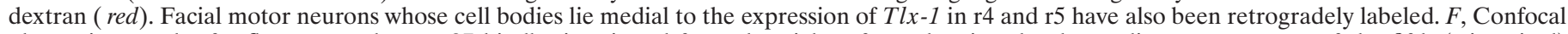

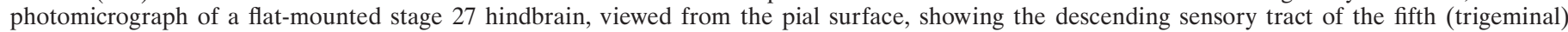

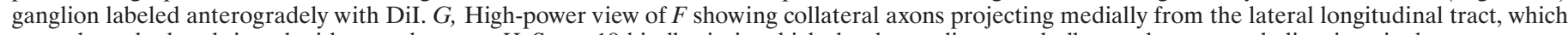

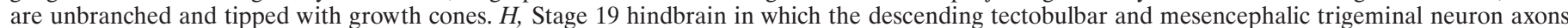

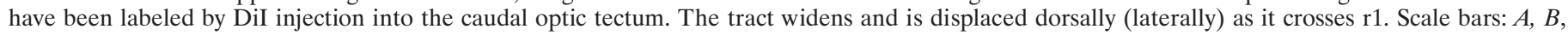
$50 \mu \mathrm{m}$; all other panels, $100 \mu \mathrm{m}$. 

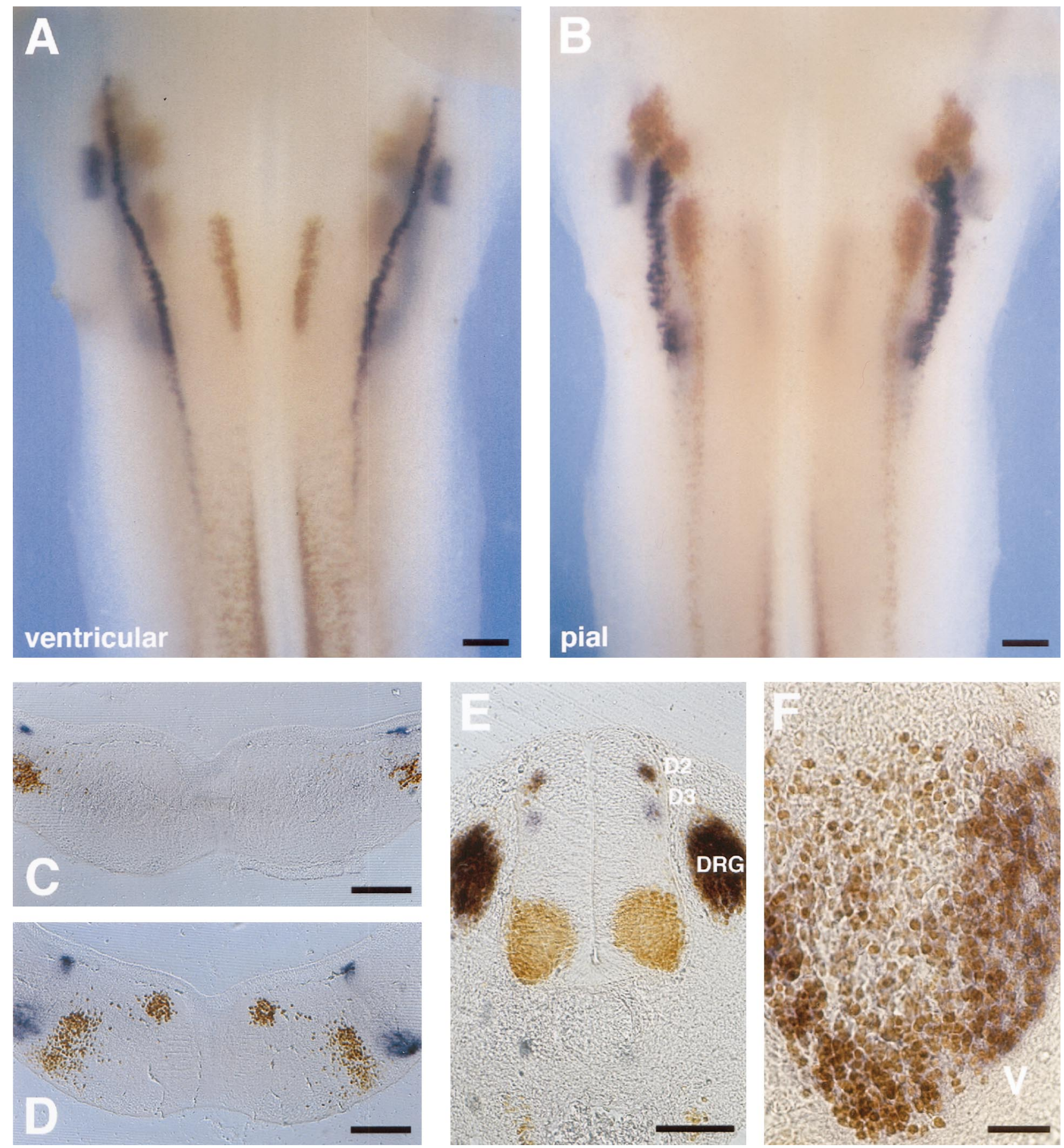

Figure 6. Colocalization of $T l x-1$ or $T l x-3$ mRNA with Isl-1/2 protein. $A$, In situ hybridization and immunohistochemical analysis of $T l x-1$ mRNA (blue) and Isl-1/2 protein (brown) expression in a flat-mounted stage 29 hindbrain, viewed from the ventricular surface. The expression of $T l x-1$ mRNA and Isl-1/2 protein are nonoverlapping. The subventricular stripe of $T l x-1$-expressing cells is sharply in focus laterally. Superficial Isl-1/2 label on either side of the midline marks the abducens nuclei (see Fig. 7). B, The same hindbrain viewed from the pial surface. Again, Tlx-1 mRNA expression (blue) and Isl-1/2 staining (brown) show distinct nonoverlapping patterns. Isl-1/2 marks motor nuclei of the fifth and seventh nerves, whereas the deep column of Tlx-1 expression defines a portion of the descending trigeminal nucleus (see Fig. 7). $C$, Transverse $50 \mu$ m vibratome section of the stage 29 hindbrain shown in $A$ and $B$ at the level of $\mathrm{r}$. At this level, Tlx-1 expression (blue) is localized only to the interface between the ventricular layer and the mantle, with no underlying deep column of expression and does not colocalize with Isl-1/2 expression in the fifth motor nuclei (brown). D, Similar section at the level of r5. The superficial and deep domains of Tlx-1 label are linked by a faint stripe of expression. The deep column of cells expressing $T l x-1$ is lateral to the Isl-1/2-positive neurons of the facial motor nucleus. The position of the column close to the pial surface, its distance from the midline, and characteristic "half-moon" shape identify it as the descending trigeminal spinal nucleus. Islet-1/2 antibody also labels the abducens nucleus that lies either side of the midline and relatively close to the ventricular surface. E, In situ hybridization and immunohistochemical analysis of $T l x-3$ mRNA (blue) and (Figure legend continues) 


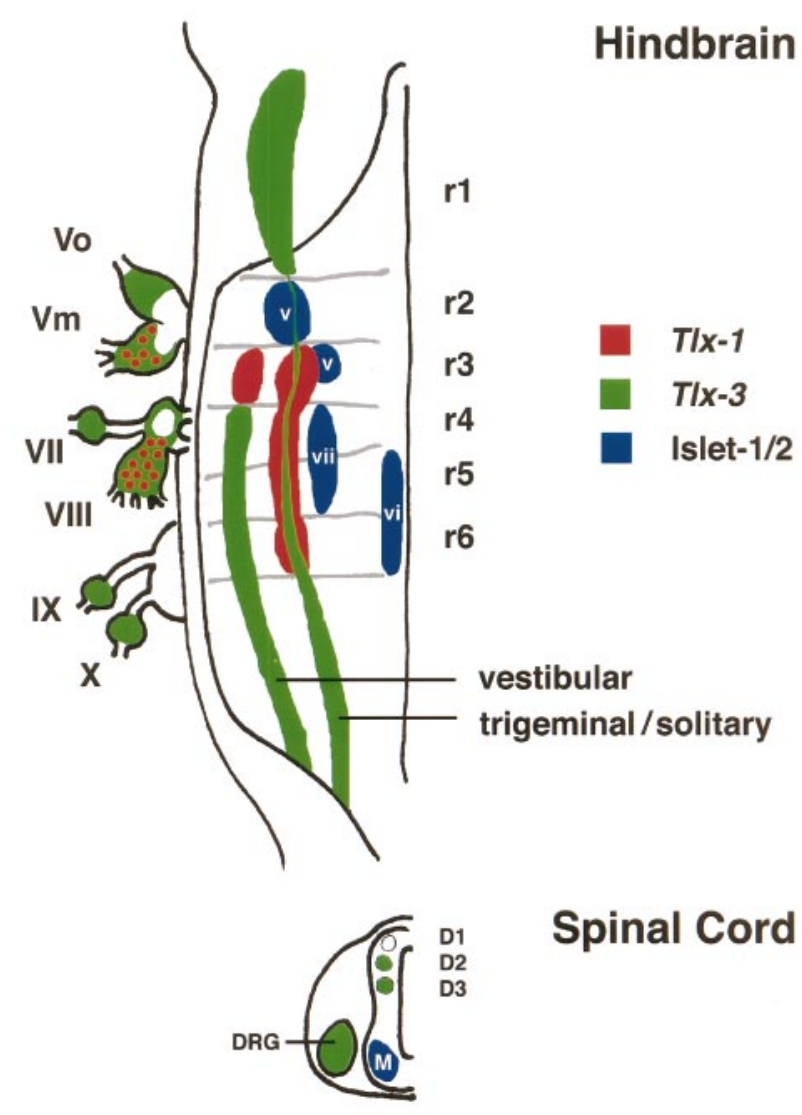

Figure 7. Summary of $T l x-1$ (red) and Tlx-3 (green) expression in the cranial ganglia, hindbrain, and spinal cord of the chick embryo. Data are pooled across developmental stages so that earlier expression in cranial ganglia can be directly compared with the pattern of labeling in emergent sensory nuclei in the hindbrain (approximately E7). The relative positions of central motor nuclei, as defined by Islet-1/2 immunostaining (blue), are shown in a schematic dorsal view of the hindbrain (top) and a schematic coronal section through the spinal cord (bottom). Rhombomere territories are delimited by gray transverse lines. Expression patterns of Tlx-1 and $T l x-3$ overlap in the distal placode-derived portions of the cranial ganglia but segregate in the hindbrain where they define separate nuclei within the vestibular and trigeminal/solitary sensory columns. Interestingly, $T l x-1$ labels a precisely defined region of the descending trigeminal spinal nucleus stretching from the $\mathrm{r} 2-\mathrm{r} 3$ to the $\mathrm{r} 6-\mathrm{r} 7$ boundaries. Vo, Ophthalmic lobe of the fifth (trigeminal) ganglion; $V m$, maxillomandibular lobe of the fifth ganglion; VII, seventh (geniculate) ganglion; VIII, eighth (vestibuloacoustic) ganglion; $I X$, ninth (petrosal) ganglion; $X$, tenth (nodose) ganglion; $v$, lateral and medial portions of the fifth motor nucleus; $v i$, abducens motor nucleus; vii, facial motor nucleus; $D 1-3$, spinal interneuron columns; $M$, spinal motor neuron column; $D R G$, dorsal root ganglion. Diagram outlines were derived from Kappers et al. (1960), Pearson (1972), Noden (1992), and Liem et al. (1997).

continue throughout the entire length of the spinal cord (summarized in Fig. 7).

As for $T l x-1$, there are transient rhombomere-specific elaborations of the $T l x-3$ expression pattern. For example, a comparison between Figures $3 B$ and $4 I$ reveals that the onset of $T l x-3$ expression within the dorsal-most column is delayed in odd-numbered rhombomeres. In addition, this column is initially expanded ventrally in both $\mathrm{r} 4$ and r6 (Fig. 4I,J). By stage 23, however, this ventral expansion is no longer visible (Fig. $4 K$; data not shown); a pattern that suggests medial to lateral cell migration similar to that noted for $T l x-1$ (see above).

Coronal sections at stages 18, 21, and 25 (Figs. $4 \mathrm{M}-\mathrm{O}$ ), show that $T l x$-3-positive cells within each column are located at the distal (pial) edge of the ventricular zone; a position similar to that found for $T l x-1$, suggesting that $T l x-3$ like $T l x-1$ is expressed in postmitotic neurons. At later developmental stages, the $T l x-3$ expression pattern becomes much more complex. Expression of the medially located cell column is still apparent within the subventricular zone at stage 30 , but the more dorsally located cell column appears to have diff used both ventrally and mediolaterally within the expanding mantle layer and now at least in part has a distinct caudal limit within the posterior hindbrain (Fig. 4L). At certain anteroposterior levels, a curtain of label can also be seen stretching from the subventricular layer through the expanding mantle layer at the same dorsoventral level as the more medially located cell column (Fig. 4P).

\section{TIX-3 is also expressed in D2 and D3 neurons in the spinal cord}

$T l x-3$ expression was also found to extend throughout the length of the spinal cord in two bilateral columns of dorsally located cells (Fig. 3G), which appear, at least initially, to be continuous with the Tlx-3-positive cell columns within the hindbrain (Fig. $4 J, K$ ). Interestingly, Liem et al. (1997) have recently defined similarly positioned columns of neuronal cells based on their expression of specific LIM homeodomain proteins. In particular, D1 neurons, which occupy the most dorsal position, express LH2 protein, whereas D2 and D3 neurons, located in progressively more ventral positions, express Isl-1 or LIM 1/2 protein, respectively. Colocalization of $T l x-3$ transcripts with Isl-1/2 protein (Fig. $6 E$ ) confirmed that the more dorsally located column of Tlx-3expressing cells marks D2 neurons, while the more ventrally located $T l x$-3-positive, Isl-1/2-negative column of cells potentially marks D3 neurons, which are known to express LIM1/2 but not Isl-1 protein (Liem et al., 1997).

Tlx-3 is also expressed throughout the mesencephalon and posterior diencephalon in scattered cells immediately adjacent to the dorsal midline (Fig. 3H).

\section{DISCUSSION}

We have isolated and characterized two members of the divergent homeobox-containing HOX11/Tlx gene family from chick, $T l x-1$ and $T l x-3$, and have shown that they are expressed in neurons in both the peripheral and central nervous systems. In the peripheral nervous system, $T l x-1$ and/or $T l x-3$ are expressed in overlapping domains in the placodally derived components of the 5th, 7th, 8th, 9th, and 10th cranial sensory ganglia. Tlx -3 , unlike $T l x-1$, is also expressed in neural crest-derived dorsal root and sympathetic ganglia. In the developing hindbrain, both genes are expressed early in bilateral columns of neurons at distinct dorsoventral levels and may delineate second order sensory nuclei. $T l x-3$ is also expressed throughout the spinal cord in dorsal

Isl-1/2 protein (brown) expression in a transverse $25 \mu \mathrm{m}$ section through the spinal cord of a stage 22 embryo. Tlx-3 is expressed within the dorsal root ganglion (DRG) and within two columns of spinal neurons (D2 and D3). Isl-1/2 staining identifies the motor neurons in the ventral spinal cord and overlaps with Tlx-3 mRNA expression in the D2 group of neurons. $F$, A high-power view of a similar transverse $25 \mu \mathrm{m}$ section through the developing fifth (trigeminal) ganglion $(V)$ showing the overlapping expression of $T l x-3$ with Isl-1/2 protein that marks peripheral sensory neurons. Scale bars: $A$, $B, E, 100 \mu \mathrm{m} ; C, D, 200 \mu \mathrm{m} ; F, 50 \mu \mathrm{m}$. 
D2 and D3 neurons and along the midline of the dorsal mesencephalon and posterior diencephalon. The expression patterns of $T l x-1$ and $T l x-3$ in the peripheral and central nervous systems suggests that these genes might be involved in the differentiation and/or survival of distinct neuronal cell types. Furthermore, $T l x$ family members define developing cranial ganglia and hindbrain sensory columns in a combinatorial manner that suggests a role in establishing appropriate connectivity.

In the peripheral nervous system, both $T l x-1$ and $T l x-3$ are transiently expressed by neurons of the developing cranial sensory ganglia. The localization of in situ labeling together with the timing of its onset and downregulation strongly suggest that only placode-derived (as opposed to neural crest-derived) neurons express $T l x-1$ and/or $T l x-3$. Fate-mapping studies have shown that placode-derived neurons associated with the 5th, 7th, 9th, and 10th cranial nerves are located distal to crest-derived neurons and, with the exception of the fifth cranial nerve, their cell bodies lie within separate ganglia (D'Amico-Martel and Noden, 1983; Noden, 1992). Neurons associated with the eighth cranial nerve are almost entirely derived from placodal ectoderm. Correspondingly, $T l x$-positive neurons are found in the geniculate, petrosal, and nodose ganglia of the 7 th, 9th, and 10th cranial nerves, respectively, in the ventrolateral portion of the trigeminal (fifth) ganglion, and throughout the whole of the vestibuloacoustic (eighth) ganglion. Furthermore, birth-dating studies have shown that cranial neural crest-derived neurons develop later than placodal neurons (D'Amico-Martel, 1982; Covell and Noden, 1989) and are still being born after $T l x$ genes have been downregulated at E4-E5. Interestingly, in the eighth ganglion, which contains the only placodal neurons to form later than day $5, T l x-1$ expression is protracted. Overall, the spatial and temporal onset of Tlx-1 and Tlx -3 expression correlates well with the predominantly rostrocaudal gradient of maturation of placodal derivatives within cranial ganglia (D’Amico-Martel, 1982).

Placodal sensory neurons are uniquely placed to play a role in pathway specification. Because they develop axons before crest derivatives, it has been suggested that they may pioneer sensory innervation of the hindbrain (Moody et al., 1989; Noden, 1992). Therefore the expression of $T l x$ family homeobox genes in subsets of placodal neurons has considerable significance. In this context, the complex expression patterns of $T l x-1$ and $T l x-3$ in the hindbrain show a remarkable correlation with the predicted synaptic targets of the corresponding sensory neurons in the periphery (summarized in Fig. 7). In the following discussion, cranial ganglia and their appropriate recipient nuclei are considered in terms of $T l x$ gene expression. In defining hindbrain sensory columns, subventricular gene expression has been interpreted as identifying recently born, immature neurons (Fig. 5D), which have yet to undergo their characteristic radial migration (Hemond and Glover, 1993; Wingate and Lumsden, 1996). The corresponding mantle expression was viewed as characterizing emergent sensory nuclei that were identified on the basis of their segmental origin (Marín and Puelles, 1995), mediolateral position, and distance from the ventricular surface.

Afferent axons from each cranial sensory ganglion form discrete parallel axon bundles in the lateral longitudinal tract (Clarke and Lumsden, 1993). Their axons subsequently develop collaterals (Fig. $5 F$ ), which synapse on sensory nuclei lying within three principal columns: the cochlear, vestibular, and trigeminal nuclear complexes. Most laterally, the cochlear nuclei (nucleus angularis, nucleus laminaris, and nucleus magnocellularis) receive input from the acoustic portion of the eighth nerve. These second-order sensory neurons are born at the rhombic lip of the fourth ventricle from E5.5 to E6.5 (Harkmark, 1954) and only subsequently migrate into the mantle. They do not appear to be labeled by either $T l x-1$ or $T l x-3$. More medially, the vestibular nucleus receives input from the eighth ganglion (which colabels with both $T l x-1$ and $T l x-3)$. Although we were not able to unequivocally locate gene expression to the various cytoarchitecturally distinct subcomponents of this complex (Wold, 1976; Glover and Petursdottir, 1988; Glover, 1993), Tlx-1 and Tlx-3 have a complementary distribution that might reflect different functional populations (summarized in Fig. 7). Tlx-1 labels a rostral column restricted to $\mathrm{r} 3$, which may represent a caudal subdivision of cell group A (Wold, 1975; Marín and Puelles, 1995). By contrast, a nonoverlapping domain of $T l x-3$ expression labels cells within the remainder of the vestibular column caudally from the r3-r4 boundary into the spinal cord where it merges with the column of D2 spinal neurons. At stage 20, there is a transient broadening of $T l x-3$ expression in $\mathrm{r} 4$ and r6 (Fig. $4 J$ ) and a transient expression of a lateral stripe of $T l x-1$ in r6 (Fig. 4A). Segment-specific developmental program may correlate with the organization of the vestibular neurons into spatially segregated clusters with different axon trajectories (Glover, 1993).

The most medial sensory recipient column is composed of the trigeminal sensory nucleus, which receives its principal input from the fifth ganglion (both $T l x-1$ - and $T l x$-3-positive), and the solitary nucleus, which has contributions from the 7 th, 9 th, and 10th ganglia (all Tlx-3-positive). Beginning at stage 25, the emergent descending trigeminal spinal nucleus labels with $T l x-1$ within a precisely defined region stretching from the $r 2-r 3$ to the r6-r7 boundaries. Segmental swellings (Fig. 6B) are consistent with origins and development of this nucleus as described in its fate map (Marín and Puelles, 1995) and may also reflect its well characterized topographical divisions into at least three subnuclei. There are prominent discontinuities in the domain of $T l x-1$ expression at the level of the r3-r4, and r5-r6 boundaries (Fig. $6 B)$. These appear to match the caudal limits of the trigeminal nucleus oralis and nucleus interpolaris respectively (Dubbeldam and Karten, 1978). Interestingly, both $T l x-1$ and $T l x-3$ are expressed in overlapping domains within the subventricular layer (Fig. 4D,L). Intermingling of $T l x-1$ and $T l x-3$ label within the trigeminal spinal nucleus itself might be expected given that the latter also receives innervation from more caudal ganglia (Dubbeldam and Karten, 1978; Dubbeldam et al., 1979). By contrast, only $T l x$-3-positive neurons are found rostrally (Fig. $4 L$ ) in the principal trigeminal nucleus that lies within r1 (Marín and Puelles, 1995). Thus, whereas $T l x-1$ primarily labels cells within the descending trigeminal spinal nucleus, $T l x-3$ labels cells within the ascending principal trigeminal nucleus. Therefore, within the ophthalmic lobe (primarily $T l x-3$-positive) and maxillomandibular lobe (both $T l x-1$ - and $T l x$-3-positive) of the fifth ganglion, the pattern of $T l x$ labeling might identify primary sensory neurons with different (ascending vs descending) axonal projections. Such a hypothesis predicts that within the colabeled maxillomandibular lobe, individual sensory neurons that express only $T l x-1$ contribute only descending (small-caliber) axons to the nucleus, whereas sensory cells with bifurcating, ascending, and descending axons (Windle, 1926) should express $T l x-3$ and $T l x-1$.

The solitary nucleus overlies and intermingles with the descending trigeminal nucleus and has a distinct adaptive structure in birds (Kappers et al., 1960). The nucleus is cytoarchitecturally distinct caudal of the r6-r7 boundary (Marín and Puelles, 1995) and extends only a thin elongation into rostral hindbrain (Dub- 
beldam et al., 1979). This reflects the poorly developed gustatory system in birds and the diminished input from the seventh nerve (Kappers et al., 1960). The pattern of $T l x-3$ labeling in caudal hindbrain seems to correspond to the structure and location of the solitary nucleus. Accordingly, the ganglia (7, 9, and 10) that project to this nucleus express $T l x-3$ but not $T l x-1$ (Fig. 7). In the spinal cord, Tlx-3 also labels D3 neurons suggesting a molecular homology between the trigeminal and solitary nuclear complex and the functionally equivalent cutaneous sensory cells in the dorsal horn.

These patterns of expression point to a functional role for Tlx proteins in establishing sensory innervation of the hindbrain. If cranial sensory innervation is orchestrated by the coordinated expression of different $T l x$ genes, both their regulation and function become issues of great developmental significance. In particular, how appropriate placodal expression is matched with the generation of recipient sensory neurons within the hindbrain is a central question. Interestingly, cell type-specific enhancer elements directing the expression of $T l x-1$ within the peripheral nervous system may already have been located. In disrupting the Tlx-1 gene, Dear et al. (1995) replaced part of the first exon and most of the first intron with an MC1-neomycin cassette and the $\beta$-galactosidase ( $\beta$-gal) gene. The resulting $\beta$-gal fusion protein is expressed in developing branchial arches, CNS, and spleen but, significantly, not within the developing cranial sensory ganglia. Therefore, tissue-specific enhancers for the expression of $T l x-1$ in placodally derived neurons probably lie within the first intron. Clues to the regulation of $T l x$ gene expression within the CNS come from the pattern of expression of $T l x-3$ in the developing spinal cord. Indeed, the homology between the vestibular and trigeminal sensory columns and D2 and D3 spinal neurons revealed by $T l x-3$ expression raises the possibility that their development is influenced by the same factors. Recent studies of dorsal spinal cord development have shown that members of the TGF- $\beta$ superfamily induce D2 and D3 interneuron differentiation (Liem et al., 1997). Therefore, the onset of Tlx-3 and possibly other Tlx family members in the hindbrain might also be regulated by the same set of roof plate-derived dorsalizing factors.

In terms of function, all Tlx proteins contain a divergent homeodomain that at least for $T l x-1$ has been shown to mediate transcriptional activity (Dear et al., 1993). In addition to the homeodomain, Tlx proteins contain four other highly conserved motifs designated TH1-TH4 (Cheng and Mak, 1993). The TH1 domain is also found in Engrailed, $m s h, N k 1, N k 2$, and goosecoid and has been shown to actively mediate transcriptional repression in vivo (Smith and Jaynes, 1996), raising the possibility that Tlx proteins function as transcriptional repressors. Recent in vitro studies have shown that $T l x-1$ expression overcomes $\mathrm{G}_{2}$ cell cycle arrest, increasing cell proliferation (Kawabe et al., 1997). However, this seems unlikely to be its function during normal neural development, given that chick $T l x-1$ is only expressed in postmitotic cells (Fig. 5C). Indeed, the coordinated expression patterns described here for $T l x-1$ and $T l x-3$ in the peripheral and central nervous systems suggest a role for $T l x$ genes in the differentiation and/or survival of distinct neuronal cell types and in specifying connectivity. In the hindbrain, despite the fact that $T l x$ genes are only expressed after the lateral longitudinal tract is formed (Moody et al., 1989; Chédotal et al., 1995), the onset of expression in sensory nuclei occurs while afferent axon collaterals are still tipped with growth cones (Fig. $6 F$ ). Hence $T l x$ genes, which are expressed both peripherally and centrally, are well placed to play a role in coordinating synaptogenesis. One model might be that $T l x$ genes directly or indirectly regulate sets of cell-cell recog- nition molecules, such as cadherins (Suzuki et al., 1997), whose presence on both presynaptic and postsynaptic elements of specific pathways might facilitate the development of appropriate connectivity. Loss-of-function mutations in mice have been made to directly test the function of one member of the $T l x$ gene family. Targeted disruption of the mouse $T l x-1$ gene results in complete agenesis of the spleen (Roberts et al., 1994; Dear et al., 1995). Although not as yet reported, our results suggest that a more subtle neuronal phenotype might also be expected in these mice. The overlapping expression patterns of different Tlx family members (Cheng and Mak, 1993; Dear et al., 1993, 1995; Raju et al., 1993; Roberts et al., 1995; Hatano et al., 1997) may, however, complicate the analysis of such loss-of-function mutations.

\section{Conclusions: a $T / x$ code for cranial sensory innervation?}

Two members of the $T l x$ homeobox gene family, $T l x-1$ and $T l x-3$, are closely associated with development of cranial sensory innervation from peripheral ganglia. We propose that both subsets of hindbrain sensory neurons and their afferent inputs are developmentally specified by the combinatorial expression of members of the $T l x$ family of transcription factors. This potential code is defined by two important criteria: (1) where one homolog defines a single hindbrain structure, for example the $T l x$-3-positive solitary nucleus, the ganglia that contribute axons (7, 9, and 10) to this nucleus will also express only this single homolog (Tlx-3); and (2) where domains of $T l x$ expression overlap in the periphery, as for example in the maxillomandibular lobe of the fifth ganglion, the corresponding hindbrain nucleus will express both genes, but in nonoverlapping territories (the $T l x$-3-positive principal trigeminal nucleus vs the $T l x$-1-positive descending trigeminal nucleus). $T l x$ genes are the first markers that distinguish subsets of hindbrain sensory nuclei. They are also among the first family of transcription factors to be described that define specific subsets of both afferent and target neurons within a general neural pathway. We expect that characterization of further family members will reveal more of the detailed sensory apparatus of the hindbrain and confirm or refute the predictions of a $T l x$ code. In addition, the continuum of $T l x-3$ expression between columns of sensory nuclei in the hindbrain and identified D2 and D3 neurons in the spinal cord suggest they are specified by a common underlying mechanism.

\section{REFERENCES}

Baptista CA, Gershon TR, Macagno ER (1990) Peripheral organs control central neurogenesis in the leech. Nature 346:855-858.

Book KJ, Morest DK (1990) Migration of neuroblasts by perikaryal translocation: role of cellular elongation and axonal outgrowth in the acoustic nuclei of the chick embryo medulla. J Comp Neurol 297:55-76.

Bottenstein JE, Sato GH (1979) Growth of a rat neuroblastoma cell line in serum-free supplemented medium. Proc Natl Acad Sci USA 76:514-517.

Chédotal A, Pourquie O, Sotelo C (1995) Initial tract formation in the brain of the chick embryo: selective expression of the BEN/SC1/DMGRASP cell adhesion molecule. Eur J Neurosci 7:198-212.

Chédotal A, Pourquie O, Ezan F, San Clemente H, Sotelo C (1996) BEN as a presumptive target recognition molecule during the development of the olivocerebellar system. J Neurosci 16:3296-3310.

Cheng SH, Mak TW (1993) Molecular characterization of three murine HOX11-related homeobox genes, $T l x-1,-2$, and -3 , and restricted expression of $T l x-1$ during embryogenesis. Dev Growth Differ 35:655-663.

Clarke J, Lumsden A (1993) Segemental repetition of neuronal phenotype sets in the chick embryo hindbrain. Development 118:151-162.

Covell D, Noden D (1989) Development of the avian embryonic trigeminal sensory-motor complex. J Comp Neurol 286:488-503.

D'Amico-Martel A (1982) Temporal patterns of neurogenesis in avian cranial sensory and autonomic ganglia. Am J Anat 163:351-372. 
D’Amico-Martel A, Noden DM (1983) Contributions of placodal and neural crest cells to avian cranial peripheral ganglia. Am J Anat 166:445-468.

Davis CA, Holmyard DP, Millen KJ, Joyner AL (1991) Examining pattern-formation in the mouse, chicken, and frog embryos with an EN-specific antiserum. Development 111:287-298.

Dear TN, Sanchez-Garcia I, Rabbitts TH (1993) The HOX11 gene encodes a DNA-binding nuclear transcription factor belonging to a distinct family of homeobox genes. Proc Natl Acad Sci USA 90:4431-4435.

Dear TN, Colledge WH, Carlton MB, Lavenir I, Larson T, Smith AJ, Warren AJ, Evans MJ, Sofroniew MV, Rabbitts TH (1995) The Hox11 gene is essential for cell survival during spleen development. Development 121:2909-2915.

Dräger UC, Edwards DL, Barnstable CJ (1984) Antibodies against filamentous components in discrete cell types of the mouse retina. J Neurosci 4:2025-2042.

Dubbeldam J, Karten H (1978) The trigeminal system in the pigeon (Columba livia). I. Projections of the gasserian ganglion. J Comp Neurol 180:661-678.

Dubbeldam J, Brus E, Menken B, Zeilstra S (1979) The central projections of the glossopharyngeal and vagus ganglia in the mallard, Anas platyrhynchos L. J Comp Neurol 183:149-168.

Dube ID, Kamel-Reid S, Yuan CC, Lu M, Wu X, Corpus G, Raimondi SC, Crist WM, Carroll AJ, Minowada J, Baker JB (1991) A novel human homeobox gene lies at the chromosome 10 breakpoint in lymphoid neoplasias with chromosomal translocation $t_{(10 ; 14)}$. Blood 78:2996-3003.

Erkman L, McEvilly RJ, Luo L, Ryan AK, Hooshmand F, O'Connell SM, Keithley EM, Rapaport DH, Ryan AF, Rosenfeld MG (1996) Role of transcription factors Brn-3.1 and Brn-3.2 in auditory and visual system development. Nature 381:603-606.

Glover J (1993) The development of brain stem projections to the spinal cord in the chicken embryo. Brain Res Bull 30:265-271.

Glover J, Petursdottir G (1988) Pathway specificity of reticulospinal and vestibulospinal projections in the 11-d chicken embryo. J Comp Neurol 270:25-38.

Gong Q, Shipley MT (1995) Evidence that pioneer olfactory axons regulate telencephalon cell cycle kinetics to induce the formation of the olfactory bulb. Neuron 14:91-101.

Hamburger V, Hamilton HL (1951) A series of normal stages in the development of the chick embryo. J Morphol 88:49-67.

Harkmark W (1954) Cell migrations from the rhombic lip to the inferior olive, the nucleus raphe and the pons. A morphological and experimental investigation of chick embryos. J Comp Neurol 100:115-209.

Hatano M, Roberts CW, Minden M, Crist WM, Korsmeyer SJ (1991) Deregulation of a homeobox gene, HOX11, by the $t(10 ; 14)$ in $\mathrm{T}$ cell leukemia. Science 253:79-82.

Hatano M, Iitsuka Y, Yamamoto H, Dezawa M, Yusa S, Kohno Y, Tokuhisa T (1997) Ncx, a Hox11 related gene, is expressed in a variety of tissues derived from neural crest cells. Anat Embryol (Berl) 195:419-425.

Hemond SG, Glover JC (1993) Clonal patterns of cell-proliferation, migration, and dispersal in the brain-stem of the chicken embryo. J Neurosci 13:1387-1402.

Heyman I, Faissner A, Lumsden A (1995) Cell and matrix specializations of rhombomere boundaries. Dev Dyn 204:301-315.

Kappers CUA, Huber GC, Crosby EC (1960) The comparative anatomy of the nervous system of vertebrates including Man. New York: Hafner.

Kawabe T, Muslin AJ, Korsmeyer SJ (1997) HOX11 interacts with protein phosphatases PP2A and PP1 and disrupts a G2/M cell-cycle checkpoint. Nature 385:454-458.

Kennedy MA, Gonzalez-Sarmiento R, Kees UR, Lampert F, Dear N, Boehm T, Rabbitts TH (1991) HOX11, a homeobox-containing T-cell oncogene on human chromosome 10q24. Proc Natl Acad Sci USA 88:8900-8904.

Kuhlenbeck H (1973) The CNS of vertebrates: a general survey of its comparative anatomy with an introduction to the pertinent functional biologic and logical concepts. II. Overall morphologic pattern. Basel: Karger.

Liem Jr KF, Tremml G, Jessell TM (1997) A role for the roof plate and its resident $\mathrm{TGFb}$-related proteins in neuronal patterning in the dorsal spinal cord. Cell 91:127-138.

Lu M, Gong ZY, Shen WF, Ho AD (1991) The tcl-3 proto-oncogene altered by chromosomal translocation in T-cell leukemia codes for a homeobox protein. EMBO J 10:2905-2910.
Lumsden A (1990) The cellular basis of segmentation in the developing hindbrain. Trends Neurosci 13:329-335.

Lumsden A, Keynes R (1989) Segmental patterns of neuronal development in the chick hindbrain. Nature 337:424-428.

Macagno ER (1979) Cellular interactions and pattern formation in the development of the visual system of daphnia magna (Crustacea, Branchiopoda). I. Interactions between embryonic retinular fibers and laminar neurons. Dev Biol 73:206-238.

Marín F, Puelles L (1995) Morphological fate of rhombomeres in quail/ chick chimeras: a segmental analysis of hindbrain nuclei. Eur J Neurosci 7:1714-1738.

Moody S, Quigg M, Frankfurter A (1989) Development of the peripheral trigeminal system in the chick revealed by an isotype-specific anti-beta-tubulin monoclonal antibody. J Comp Neurol 279:567-580.

Noden DM (1992) Cell movements and control of patterned tissue assembly during craniofacial development. J Craniofac Genet Dev Biol 11:192-213.

Pattyn A, Morin X, Cremer H, Goridis C, Brunet JF (1997) Expression and interactions of the two closely related homeobox genes Phox $2 \mathrm{a}$ and Phox2b during neurogenesis. Development 124:4065-4075.

Pearson R (1972) The avian brain. London: Academic.

Pimenta AF, Zhukareva V, Barbe MF, Reinoso BS, Grimley C, Henzel W, Fischer I, Levitt P (1995) The limbic system-associated membrane protein is an Ig superfamily member that mediates selective neuronal growth and axon targeting. Neuron 15:287-297.

Raju K, Tang S, Dube ID, Kamel-Reid S, Bryce DM, Breitman ML (1993) Characterization and developmental expression of Tlx-1, the murine homolog of HOX11. Mech Dev 44:51-64.

Roberts CW, Shutter JR, Korsmeyer SJ (1994) Hox11 controls the genesis of the spleen. Nature 368:747-749.

Roberts CW, Sonder AM, Lumsden A, Korsmeyer SJ (1995) Development expression of Hox11 and specification of splenic cell fate. Am J Pathol 146:1089-1101.

Saito T, Greenwood A, Sun Q, Anderson DJ (1995) Identification by differential RT-PCR of a novel paired homeodomain protein specifically expressed in sensory neurons and a subset of their CNS targets. Mol Cell Neurosci 6:280-292.

Selleck SB, Steller H (1991) The influence of retinal innervation on neurogenesis in the first optic ganglion of Drosophila. Neuron 6:83-99.

Smith ST, Jaynes JB (1996) A conserved region of engrailed, shared among all en-, gsc-, Nk1-, Nk2- and msh-class homeoproteins, mediates active transcriptional repression in vivo. Development 122:3141-3150.

Suzuki SC, Inoue T, Kimura Y, Tanaka T, Takeichi M (1997) Neuronal circuits are subdivided by differential expression of type- II classic cadherins in postnatal mouse brains. Mol Cell Neurosci 9:433-447.

Tanabe Y, Jessell TM (1996) Diversity and pattern in the developing spinal cord. Science 274:1115-1123.

Tiveron MC, Hirsch MR, Brunet JF (1996) The expression pattern of the transcription factor Phox 2 delineates synaptic pathways of the autonomic nervous system. J Neurosci 16:7649-7660.

Tsuchida T, Ensini M, Morton SB, Baldassare M, Edlund T, Jessell TM, Pfaff SL (1994) Topographic organization of embryonic motor neurons defined by expression of LIM homeobox genes [see comments]. Cell 79:957-70.

Turner EE, Jenne KJ, Rosenfeld MG (1994) Brn-3.2: a Brn-3-related transcription factor with distinctive CNS expression and regulation by retinoic acid. Neuron 12:205-218.

Varela-Echavarría A, Pfaff SL, Guthrie S (1996) Differential expression of LIM homeobox genes among motor neuron subpopulations in the developing chick brain stem. Mol Cell Neurosci 8:242-257.

Wilkinson DG (1992) Whole-mount in situ hybridization of vertebrate embryos. In: In situ hybridization (Wilkinson DG, ed), pp 75-83. Oxford: IRL.

Windle W (1926) Nonbifurcating nerve fibers of the trigeminal nerve. J Comp Neurol 40:229-240.

Wingate RJT, Lumsden A (1996) Persistence of rhombomeric organization in the postsegmental hindbrain. Development 122:2143-2152.

Wold J (1975) The distribution of primary afferents to the vestibular nuclei in the domestic hen (Gallus domesticus). Brain Res 95:531-543.

Wold J (1976) The vestibular nuclei in the domestic hen (Gallus domesticus). I. Normal anatomy. Anat Embryol (Berl) 149:29-46.

Xiang M, Zhou L, Macke JP, Yoshioka T, Hendry SH, Eddy RL, Shows TB, Nathans J (1995) The Brn-3 family of POU-domain factors: primary structure, binding specificity, and expression in subsets of retinal ganglion cells and somatosensory neurons. J Neurosci 15:4762-4785. 